\title{
Inhibition of canonical WNT signaling pathway by $\beta$-catenin/CBP inhibitor ICG-001 ameliorates liver fibrosis in vivo through suppression of stromal CXCL12
}

\author{
Büsra Öztürk Akcora ${ }^{\mathrm{a}}$, Gert Storm ${ }^{\mathrm{a}, \mathrm{b}}$, Ruchi Bansal ${ }^{\mathrm{a}, *}$ \\ a Targeted Therapeutics, Department of Biomaterials Science and Technology, MIRA Institute for Biomedical Technology and Technical Medicine, Faculty of Science and \\ Technology, University of Twente, Enschede, The Netherlands \\ b Department of Pharmaceutics, Utrecht Institute of Pharmaceutical Sciences, Faculty of Science, Utrecht University, Utrecht, The Netherlands
}

\section{A R T I C L E I N F O}

\section{Keywords:}

Wnt signaling pathway

Myofibroblasts

CXCL12

Liver fibrosis

Intrahepatic inflammation

Angiogenesis

\begin{abstract}
A B S T R A C T
Quiescent hepatic stellate cells (HSCs), in response to liver injury, undergo characteristic morphological transformation into proliferative, contractile and ECM-producing myofibroblasts. In this study, we investigated the implication of canonical Wnt signaling pathway in HSCs and liver fibrogenesis. Canonical Wnt signaling pathway activation and inhibition using $\beta$-catenin/CBP inhibitor ICG001 was examined in-vitro in TGF $\beta$-activated 3T3, LX2, primary human HSCs, and in-vivo in $\mathrm{CCl}_{4}$-induced acute liver injury mouse model. Fibroblastsconditioned medium studies were performed to assess the Wnt-regulated paracrine factors involved in crosstalk between HSCs-macrophages and HSCs-endothelial cells. Canonical Wnt signaling pathway components were significantly up-regulated in-vitro and in-vivo. In-vitro, ICG-001 significantly inhibited fibrotic parameters, 3Dcollagen contractility and wound healing. Conditioned medium induced fibroblasts-mediated macrophage and endothelial cells activation was significantly inhibited by ICG-001. In-vivo, ICG-001 significantly attenuated collagen accumulation and HSC activation. Interestingly, ICG-001 drastically inhibited macrophage infiltration, intrahepatic inflammation and angiogenesis. We further analyzed the paracrine factors involved in Wnt-mediated effects and found CXCL12 was significantly suppressed both in-vitro and in-vivo following Wnt inhibition. Wnt-regulated CXCL12 secretion from activated HSCs potentiated macrophage infiltration and activation, and angiogenesis. Pharmacological inhibition of canonical Wnt signaling pathway via suppression of stromal CXCL12 suggests a potential therapeutic approach targeting activated HSCs in liver fibrosis.
\end{abstract}

\section{Introduction}

Liver fibrosis is a leading and growing cause of mortality worldwide $[1,2]$. Hepatocellular damage, inflammatory cells infiltration and extensive tissue remodeling, vascular disorganization and tissue hypoxia ultimately culminate into progressive fibrosis, cirrhosis or end-stage liver failure [3]. Irrespective of disease etiology, hepatic stellate cells (HSCs) are recognized as the major cellular origin of fibrogenic myofibroblasts during chronic liver disease. In response to liver injury, HSCs undergo a phenotypic trans-differentiation into highly proliferative, contractile and ECM-producing myofibroblasts, and are the major effector cells involved in the pathogenesis of fibrogenesis [4-6]. The molecular mechanisms leading to aberrant activation of HSCs and regulatory cell signaling processes involved are incompletely understood, and therefore molecular therapies for the treatment of liver fibrosis are not yet available for clinical use.

Growing evidence suggests that there exists a positive interplay between HSCs and inflammatory macrophages that strongly contribute

\footnotetext{
Abbreviations: ECM, extracellular matrix; HSCs, hepatic stellate cells; $\mathrm{CCl}_{4}$, carbon tetrachloride; TGF $\beta$, transforming growth factor beta; mRNA, messenger RNAs; qRT-PCR, quanti-

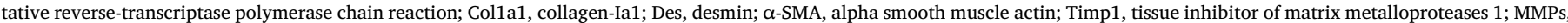

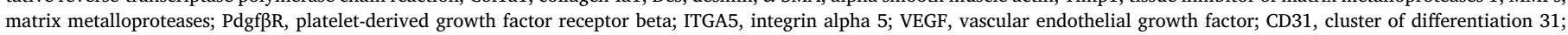

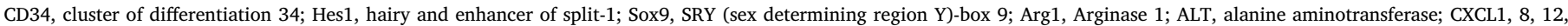

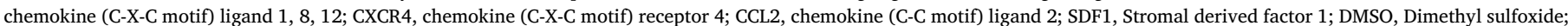

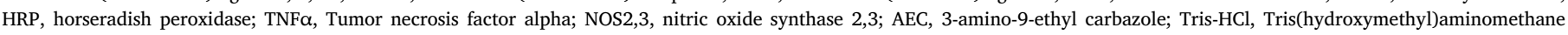

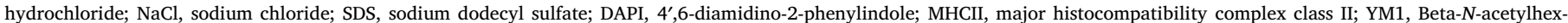
osaminidase or Chi313, Chitinase-3-like protein 3; MIF, macrophage migration inhibitory factor; IL-1 $\beta$, Interleukin 1 beta

* Corresponding author at: Targeted Therapeutics, Department of Biomaterials, Science and Technology, MIRA Institute for Biomedical Technology and Technical Medicine, University of Twente, Drienerlolaan 5, 7522 NB Enschede, The Netherlands.

E-mail address: R.Bansal@utwente.nl (R. Bansal).
} 
to the amplification of fibrosis [7]. Following recruitment or tissue-resident macrophage proliferation, monocytes undergo differentiation into two distinct subsets of macrophages that are categorized as classically-activated inflammatory M1-like macrophages or alternativelyactivated restorative M2-like macrophages. Inflammatory macrophages produce pro-fibrotic mediators and chemokines that directly activate and recruit fibroblasts and inflammatory cells thereby further worsening the disease course [8-10]. Furthermore, there is considerable evidence that angiogenesis contributes significantly to the progression of fibrosis during chronic liver damage [11,12]. HSCs activation, in response to hypoxia, play a key role in angiogenesis through interactions with endothelial cells via paracrine factors including PDGF and VEGF. Furthermore, liver sinusoidal endothelial cells (LSECs) are required to maintain HSCs quiescence, and upon activation, partially via HSCs, become pro-inflammatory and therefore also play a critical role in intrahepatic inflammation [13-15]. These data suggests the multifaceted role of HSCs in exaggerating inflammation and angiogenesis via paracrine interactions, and via autocrine signaling maintain the myofibroblastic differentiation during fibrosis progression.

Recent studies support that tissue injury and liver regeneration are associated with the reactivation of several highly conserved developmental morphogenic signaling pathways including Hedgehog (Hh), Notch and Wnt [16]. Upregulation of these morphogens and their signaling are involved in HSCs activation and, inhibition of these pathways strongly attenuated fibrogenesis as examined in experimental fibrosis models [16,17]. Morphogens may also facilitate cross-talk between HSC and hepatic progenitor cells or hepatocytes to stimulate liver regeneration, however these morphogens are also implicated in liver tumorigenesis. Since the regulation of these morphogens is highly complex, it is very crucial to understand the mechanisms by which they control HSC phenotype and activation for the identification of more precise therapeutic targets.

Among morphogens, Wnts are a highly conserved family of secreted glycoproteins that plays an essential role in organogenesis and tissue homeostasis $[18,19]$. Wnt proteins transmit their signal by interacting with Frizzled (Fzd) receptors and low-density lipoprotein receptor-related protein co-receptors (LRP5/6) [20,21]. Upon binding to their receptors, Wnt proteins induce a cascade of intracellular downstream signaling events involving Disheveled, Axin and glycogen synthase kinase $3 \beta$ resulting in dephosphorylation of $\beta$-catenin, that culminates in the stabilization of $\beta$-catenin and its translocation to the nucleus [22]. Nuclear $\beta$-catenin then binds to T-cell factor/lymphoid enhancerbinding factor (Tcf/lef) and recruits transcriptional co-activators, cAMP-response element-binding protein (CREB-binding protein or CBP) or P300, to stimulate transcription of Wnt target genes. In addition to this canonical pathway, certain Wnt proteins exert their effects by activation of the planar cell polarity (PCP) pathway or the non-canonical calcium/calmodulin-dependent kinase pathway [23,24].

Accumulating evidence indicates that increased activation of canonical Wnt signaling might have an important role in fibrogenesis. So far, pathologically activated canonical Wnts has been implicated in the pathogenesis of pulmonary, kidney and liver fibrosis [25-31]. Wnt signaling has been shown to be activated in HSCs upon liver injury and the increased expression of many components of different Wnt pathways including Wnt ligands, Frizzled receptors, LRP5/6 co-receptor and $\beta$-catenin have been documented during HSCs trans-differentiation. Furthermore, studies have demonstrated downregulation of the Wnt/ $\beta$ catenin signaling pathway significantly inhibits HSCs activation and fibrogenesis [32,33]. However, the role of canonical Wnt signaling pathway in HSCs is still unclear and the underlying mechanism involved in reduction of fibrogenesis is still not well defined.

In this study, we have investigated the effects of ICG-001, a selective Wnt/ $\beta$-catenin/CBP inhibitor, on HSCs activation in vitro and in vivo in acute $\mathrm{CCl}_{4}$-induced liver injury mouse model. We further investigated the paracrine factors regulated by Wnt signaling pathway that regulates HSCs activation, and HSCs-driven inflammation and angiogenesis.

\section{Materials and methods}

\subsection{Cell lines}

Human hepatic stellate cells (LX2 cells), immortalized human-derived cell line was kindly provided by Prof. Scott Friedman (Mount Sinai Hospital, New York, NY, USA). Murine H5V heart capillary endothelial cells were kindly provided by Dr. A. Vecchi (Mario Negri, Institute for Pharmacological Research, Milano, Italy). Murine NIH3T3 fibroblasts and murine RAW264.7 macrophages were obtained from American Type Culture Collection (ATCC, Manassas, VA, USA). LX2 cells were cultured in DMEM-Glutamax (Invitrogen, Carlsbad, CA, USA) supplemented with $10 \%$ FBS and antibiotics $(50 \mathrm{U} / \mathrm{ml}$ Penicillin and $50 \mu \mathrm{g} / \mathrm{ml}$ streptomycin, Sigma, St. Louis, MO, USA). RAW macrophages were cultured in Roswell Park Memorial Institute (RPMI) 1640 medium (Lonza, Verviers, Belgium), and 3T3 and H5V cells were cultured in Dulbecco's modified Eagle's (DMEM) medium (Lonza) supplemented with $2 \mathrm{mM}$ L-glutamine (Sigma), 10\% fetal bovine serum (FBS, Lonza) and antibiotics (50 U/ml Penicillin and $50 \mu \mathrm{g} / \mathrm{ml}$ streptomycin, Sigma).

\subsection{Primary human cells}

Primary human hepatic stellate cells (pHSCs), liver sinusoidal endothelial cells (pLSECs) and Kupffer cells were obtained from ScienCell (Sciencell, Carlsbad, CA, USA). pHSCs were cultured on poly(L-lysine) coated plates in stellate cell medium (SteCM, ScienCell) supplemented with stellate cells growth supplements (SteCGS), 2\% FBS and antibiotics. pLSECs were cultured on fibronectin-coated plates in endothelial cell medium (ECM, ScienCell) supplemented with endothelial cells growth supplements (ECGS), 5\% FBS and antibiotics. Primary human Kupffer cells were cultured on poly(L-lysine) coated plates in macrophage medium (MM, ScienCell) supplemented with macrophage growth supplements (MaGS), 5\% FBS and antibiotics. All the primary human cells were passaged in their respective complete culture medium as per manufacturer's instructions. Cells were used between passage 2 and passage 7. All the primary cells were characterized using their specific markers expression e.g. pHSCs were characterized by $\alpha$-SMA expression.

\subsection{Effects of Wnt/ $\beta$-catenin inhibitor ICG001 in mouse $3 T 3$ fibroblasts, human LX2 cells and primary human HSCs}

Wnt/ $\beta$-catenin inhibitor ICG-001 used in the study has been purchased from Selleckchem (Houston, TX, USA). ICG-001 selectively antagonizes Wnt/ $\beta$-catenin/TCF-mediated transcription and specifically binds to CREB-binding protein (CBP) [34]. ICG-001 Cells were seeded in 24 -well plates $\left(5 \times 10^{4}\right.$ cells/well $)$ and 12 -well plates $\left(1 \times 10^{5}\right.$ cells/ well) and cultured overnight. To assess the effects on fibrotic parameters, cells were starved for $24 \mathrm{~h}$ with serum-free medium and then incubated with starvation medium alone, $1 \mu \mathrm{M}$ and/or $5 \mu \mathrm{M}$ ICG-001 (Selleckchem, Houston, TX, USA) with $5 \mathrm{ng} / \mathrm{ml}$ of human recombinant TGF $\beta 1$ (Roche, Mannheim, Germany) for $24 \mathrm{~h}$. Cells (24-well plates) were then fixed with chilled acetone:methanol (1:1) for $20 \mathrm{~min}$, dried and stained for different markers (collagen-I, $\alpha$-SMA and vimentin) (antibodies are summarized in Supplementary Table 1). In addition, cells (12-well plates) were lysed with RNA lysis buffer to perform quantitative real-time PCR analyses. Experiments were performed as three independent experiments. Samples were also prepared from LX2 cells for western blot analysis for the assessment of intracellular and extracellular collagen-I expression.

\section{4. $3 D$ collagen-I gel contraction assay}

A collagen suspension $(5.0 \mathrm{ml})$ containing $3.0 \mathrm{ml}$ Collagen G1 ( $5 \mathrm{mg} / \mathrm{ml}$, Matrix biosciences, Mörlenbach, Germany), $0.5 \mathrm{ml} 10 \times$ M199 medium, $85 \mu \mathrm{l} 1 \mathrm{~N} \mathrm{NaOH}$ (Sigma) and sterile water was prepared 
and then mixed with $1.0 \mathrm{ml}\left(2 \times 10^{6}\right)$ cells. Collagen gel-cells suspension $(0.6 \mathrm{ml} /$ well $)$ was plated in a 24-well culture plate and allowed to polymerize for $1 \mathrm{~h}$ at $37^{\circ} \mathrm{C}$. Polymerized gel was then incubated with $1 \mathrm{ml}$ of serum-free medium with or without TGF $\beta(5 \mathrm{ng} / \mathrm{ml})$ together with $5 \mu \mathrm{M}$ ICG-001 followed by detachment of the gels from the culture wells. Photographs were made with a digital camera at different time points $(0,24,48$ and $72 \mathrm{~h})$. The size of the gels were digitally measured and normalized with their respective well size in each image. Gel contraction experiments were performed in duplicates in three independent experiments.

\subsection{Scratch wound healing assay}

LX2 cells were plated in 12-well culture plates $\left(1 \times 10^{5}\right.$ cells/well $)$ for $24 \mathrm{~h}$ and starved overnight in serum-free medium. A standardized scratch was made using a $200 \mu \mathrm{l}$ pipette tip fixed in a custom-designed holder. Then, cells were washed and incubated with $1 \mathrm{ml}$ of $0.5 \%$ FBS containing medium with or without TGF $\beta(5 \mathrm{ng} / \mathrm{ml})$ together with $5 \mu \mathrm{M}$ ICG-001. To measure the migratory response of the cells into the scrape wounds, microscopic photographs were taken at $0 \mathrm{~h}$ and $24 \mathrm{~h}$. Images were analyzed by NIH ImageJ software (NIH, Bethesda, MD, USA) to calculate the area of scratch-wound and represented as \% of wound healed relative to the control wells. Wound healing experiments were performed in duplicates in three independent experiments.

\subsection{Cell viability assay}

To assess effects on cell viability, cells plated in 96 well plates were serum-starved for $24 \mathrm{~h}$ and incubated with different concentrations of ICG-001 (0.1, 0.5, 1.0, 2.5, 5, 10 and $25 \mathrm{uM})$ for $24 \mathrm{~h}$. Cell viability assay was performed using Alamar Blue reagent (Invitrogen) as per manufacturer's instructions. The results are represented as \% cell viability normalized to untreated control cells (at 100\%). All measurements were performed in triplicates in three independent experiments.

\subsection{Animal experiments}

All the animal experiments in this study were performed in strict accordance with the guidelines and regulations for the Care and Use of Laboratory Animals, Utrecht University, The Netherlands. The protocols were approved by the Institutional Animal Ethics Committee of the University of Twente, The Netherlands. 6- to 8-week old C57BL/6 male mice were purchased from Harlan (Zeist, Netherlands) and kept at $12 \mathrm{~h}$ light/12 $\mathrm{h}$ dark cycles with ad libitum normal diet.

\section{8. $\mathrm{CCl}_{4}$-induced acute liver injury mouse model}

To study the effect of ICG001, male C57BL/ 6 mice were treated with a single intraperitoneal injection of olive-oil or $\mathrm{CCl}_{4}(1 \mathrm{ml} / \mathrm{kg}$ in oliveoil) at day 1 . At day 2 and day $3, \mathrm{CCl}_{4}$-treated mice received intraperitoneal administration of $5 \mathrm{mg} / \mathrm{kg} \beta$-catenin/CBP inhibitor ICG001 prepared in 1\% DMSO (Sigma) and 5\% $\beta$-hydroxycyclodextrin (Sigma) or vehicle treatment (1\%DMSO/5\% $\beta$-hydroxycyclodextrin/ PBS) ( $n=5$ per group). At day 4 , all mice were sacrificed and livers were harvested for the subsequent analysis.

\subsection{Hydroxyproline assay}

Hepatic collagen content was determined by liver hydroxyproline assay as reported, with minor modifications [35]. The relative hydroxyproline (mg/g liver) was calculated based on individual liver weights.

\subsection{Immunohistochemistry}

Liver tissues were harvested and transferred to Tissue-Tek OCT embedding medium (Sakura Finetek, Torrance, CA, USA), and snap- frozen in 2-methyl butane chilled on a dry ice. Cryosections $(4 \mu \mathrm{m})$ were cut using a Leica CM 3050 cryostat (Leica Microsystems, Nussloch, Germany). The sections were air-dried and fixed with acetone for 10 min. Cells or tissue sections were rehydrated with PBS and incubated with the primary antibody (refer to Supplementary Table 1) for $1 \mathrm{~h}$ at room temperature. Cells or sections were then incubated with horseradish peroxidase (HRP)-conjugated secondary antibody for $1 \mathrm{~h}$ at room temperature. Then incubated with HRP-conjugated tertiary antibody for $1 \mathrm{~h}$ at room temperature. Thereafter, peroxidase activity was developed using AEC (3-amino-9-ethyl carbazole) substrate kit (Life Technologies, Carlsbad, CA, USA) for $20 \mathrm{~min}$ and nuclei were counterstained with hematoxylin (Sigma). For tissue sections, endogenous peroxidase activity was blocked by $3 \% \mathrm{H}_{2} \mathrm{O}_{2}$ prepared in methanol. Cells or sections were mounted with Aquatex mounting medium (Merck, Darmstadt, Germany). The staining was visualized and the images were captured using light microscopy (Nikon eclipse E600 microscope, Nikon, Tokyo, Japan). Furthermore, sections were scanned using Hamamatsu NanoZoomer Digital slide scanner 2.0HT (Hamamatsu Photonics, Bridgewater, NJ, USA) for quantitative histological analysis. High resolution scans were viewed using NanoZoomer Digital Pathology (NDP2.0) viewer software (Hamamatsu Photonics). About 20 images $(100 \times)$ of each entire section (from NDP) were imported into ImageJ and were analyzed quantitatively at a fixed threshold. All the primary antibodies used in this study have been pretested for specificity. The staining's performed in the study included the negative control (without primary antibody) to confirm the specificity of the staining and showed no non-specific staining (data not shown).

\subsection{Western blot analysis}

Cells or liver tissues were homogenized in cold RIPA buffer [50 mM Tris- $\mathrm{HCl}, 150 \mathrm{mM} \mathrm{NaCl}, 0.1 \%$ SDS, $0.1 \%$ Igepal in $0.5 \%$ sodium deoxycholate with 1 tablet of protease inhibitor cocktail and 1 tablet of phosphatase inhibitor (Roche) in $10 \mathrm{ml}$ on ice with a tissue homogenizer and the lysates were centrifuged at $12,000 \mathrm{rpm}$ for $1 \mathrm{~h}$ at $4{ }^{\circ} \mathrm{C}$. The supernatants were stored at $-70{ }^{\circ} \mathrm{C}$ until use. The samples were boiled in standard protein sample buffer and subjected to SDS-PAGE with $10 \%$ Tris-glycine gels (Life Technologies) followed by transfer to PVDF membrane. The membranes were developed according to the standard protocols using primary and secondary antibodies as mentioned in Supplementary Table 1. The bands were visualized using ECL detection reagent (PerkinElmer, Waltham, MA, USA) and photographed using FluorChem Imaging System (ProteinSimple, Alpha Innotech, San Leandro, CA, USA). Intensity of individual bands was quantified using ImageJ, and expressed in $\%$ relative to $\beta$-actin.

\subsection{RNA extraction, reverse transcription, quantitative real time PCR and RT2 profiler PCR array}

Total RNA from cells and liver tissues was isolated using GenElute Total RNA Miniprep Kit (Sigma) and SV total RNA isolation system (Promega Corporation, Fitchburg, WI, USA) respectively according to manufacturer's instructions. The RNA concentration was quantitated by a UV spectrophotometer (NanoDrop Technologies, Wilmington, DE, USA). Total RNA $(1 \mu \mathrm{g})$ was reverse-transcribed using iScript cDNA Synthesis Kit (Bio-Rad, Hercules, CA, USA). All the primers were purchased from Sigma-Genosys (Haverhill, UK). Real-time PCR was performed using $2 \times$ SensiMix SYBR and Fluorescein Kit (Bioline, QT61505, Luckenwalde, Germany), 20 ng cDNA and pre-tested gene-specific primer sets (listed in Supplementary Tables 2 and 3). The cycling conditions for the BioRad CFX384 Real-Time PCR detection system were $95^{\circ} \mathrm{C}$ for $10 \mathrm{~min}, 40$ cycles of $95{ }^{\circ} \mathrm{C} / 15 \mathrm{~s}, 58{ }^{\circ} \mathrm{C} / 15 \mathrm{~s}$ and $72{ }^{\circ} \mathrm{C} /$ $15 \mathrm{~s}$. Finally, cycle threshold $(\mathrm{Ct})$ values were normalized to reference gene GAPDH and fold changes in expression were calculated using the $2^{-\Delta \Delta \mathrm{Ct}}$ method. 


\subsection{Cytokine proteome profiler protein array}

pHSCs were plated in complete stellate cell medium (SteCM, ScienCell) in 12-well plates and cultured overnight followed by serumstarvation for $24 \mathrm{~h}$. pHSCs were then incubated with or without TGF $\beta$ $(5 \mathrm{ng} / \mathrm{ml}) \pm$ ICG-001 $(5 \mu \mathrm{M})$. After $24 \mathrm{~h}$, cells were washed and fresh starvation medium was added. After $24 \mathrm{~h}$, conditioned medium was collected and stored at $-70{ }^{\circ} \mathrm{C}$ until use. Relative protein expression levels of 36 different cytokines and chemokines were evaluated in cell culture supernatant (conditioned medium) using a Proteome Profiler Human Cytokine Array Kit (Cat. No. ARY005B, R\&D Systems, Minneapolis, MN, USA) according to the manufacturer's instructions. Pixel density in each spot of the array was quantified using ImageJ. Cytokines detectable by the antibody array kit included: C5a, CD40 ligand, G-CSF, GM-CSF, CXCL1/GRO- $\alpha$, CCL1/I-309, IFN- $\gamma$, IL-1 $\alpha$, IL1ß, IL-1Ra, IL-2, IL-4, IL-5, IL-6, IL-8, IL-10, IL-12 p70, IL-13, IL-16, IL17, IL-17E, IL-18, IL-21, IL-27, IL-32 $\alpha$, CXCL10/IP-10, CXCL11/I-TAC, CCL2/MCP-1, MIF, MIP-1 $\alpha$ /MIP-1 $\beta$, RANTES/CCL5, SDF-1/CXCL12, Serpin E1/PAI-1, TNF- $\alpha$ and TREM-1.

\subsection{Conditioned medium studies}

3T3 fibroblasts were plated in complete DMEM medium in 12-well plates and cultured overnight followed by serum-starvation for $24 \mathrm{~h}$. 3T3 fibroblasts were then incubated with or without TGF $\beta$ ( $5 \mathrm{ng} /$ $\mathrm{ml}) \pm$ ICG-001 $(5 \mu \mathrm{M})$. After $24 \mathrm{~h}$, incubated cells were washed and fresh medium ( $0 \%$ FBS) was added. After $24 \mathrm{~h}$, conditioned medium was collected and stored at $-70{ }^{\circ} \mathrm{C}$ until use. 3T3 conditioned medium (from different conditions) was added on unstimulated RAW macrophages and H5V endothelial cells with an equal volume of fresh respective medium to avoid nutrient depletion effects. After $24 \mathrm{~h}$ incubation with the conditioned medium, cells were lysed for quantitative PCR analysis. All the conditioned medium studies were performed in three independent experiments.

\subsection{Tube formation assay}

The fibroblasts-mediated paracrine effects of fibroblasts on endothelial cells (H5V) were examined using the tube formation assay. Geltrex $^{\mathrm{TM}}$ reduced growth factor basement membrane matrix (Invitrogen) was thawed at $4{ }^{\circ} \mathrm{C}$ overnight before use. Geltrex ${ }^{\mathrm{TM}}$ matrix was added to wells of a 8- Lab-Tek ${ }^{\mathrm{TM}}$ chambered slides (Nalge Nunc, Naperville, IL, USA) $(150 \mu \mathrm{l} /$ well $)$ and then incubated at $37^{\circ} \mathrm{C}$ for $1 \mathrm{~h}$ to allow polymerization. $\mathrm{H} 5 \mathrm{~V}$ cells $(40,000$ cells/well) were seeded onto the layer of Geltrex ${ }^{\mathrm{TM}}$ matrix containing the conditioned medium collected from 3T3 cells after different treatment as mentioned above or CXCL12 $(100 \mathrm{ng} / \mathrm{ml})$ was added as control. Additionally, CXCL12 antibody $(10 \mu \mathrm{g} / \mathrm{ml})$ was added in TGF $\beta$-stimulated 3T3-conditioned medium to examine the effect of CXCL12 blocking. After $20 \mathrm{~h}$ at $37^{\circ} \mathrm{C}$, 5 random selected fields of view were captured using EVOS fluorescent microscope (AMG, Life Technologies). Tube formation was quantified by measuring the number of tubes counted and represented as relative percentage of tube formation.

\subsection{Transwell migration assay}

The transwell migration assay was performed on RAW macrophages using a polycarbonate membrane inserts $(8-\mu \mathrm{m}$ pore size; Transwell Corning Costar, Cambridge, MA, USA). The lower chambers were filled with 650ul medium (455ul of conditioned medium $+175 \mathrm{ul}$ of fresh medium). The conditioned medium was collected from 3T3 cells after different treatment as mentioned above or CXCL12 $(100 \mathrm{ng} / \mathrm{ml})$ was added as control. Additionally, CXCL12 antibody $(10 \mu \mathrm{g} / \mathrm{ml})$ was added in TGF $\beta$-stimulated 3T3-conditioned medium to examine the effect of CXCL12 blocking. RAW cells $\left(1 \times 10^{5}\right.$ cells/100ul) were added to the upper chamber. Cells were then incubated at $37^{\circ} \mathrm{C}$ for $24 \mathrm{~h}$ to allow cell migration through the membrane. After incubation, the chambers were removed and washed twice with PBS and the non-invading cells were discarded using a cotton swab. The cells were then fixed in $4 \%$ paraformaldehyde, permeabilized in $100 \%$ methanol and stained using DAPI nuclear stain. 5 random selected fields of view were captured using EVOS fluorescent microscope and the number of invading cells were quantified using ImageJ and represented as relative percentage of cell migration.

\subsection{Statistical analyses}

All the data are presented as mean \pm standard error of the mean (SEM). The graphs and statistical analyses were performed using GraphPad Prism version 5.02 (GraphPad Prism Software, La Jolla, CA, USA). Comparison to control group were analyzed using unpaired students' $t$-test while multiple comparisons between different groups were performed by one-way analysis of variance (ANOVA) with Bonferroni post-hoc test. The differences were considered significant at $\mathrm{p}<0.05$.

\section{Results}

\subsection{Up-regulation of canonical Wnt signaling pathway components in mouse $3 T 3$ fibroblasts upon TGFB-activation}

We first examined the expression of canonical Wnt signaling pathway components i.e. canonical Wnt proteins, Wnt frizzled receptors and low-density lipoprotein receptor-related protein co-receptor (LRP6) in TGF $\beta$-activated murine 3T3 fibroblasts. We observed significant upregulation of canonical Wnts (Wnt1, Wnt3a and Wnt10b), Wnt frizzled receptors (FZD1, FZD2) and Wnt co-receptor (LRP6) in TGF $\beta$-activated 3T3 fibroblasts as compared to non-activated 3T3 cells (Fig. 1A). The hallmark of canonical Wnt signaling pathway is that it activates $\beta$-catenin nuclear translocation where it binds to Tcf/Lef to induce expression of Wnt target genes e.g. Axin-2. To determine the activation of canonical Wnt signaling pathway, we analyzed the gene expression of $\beta$-catenin and Axin-2. We observed significant upregulation of both $\beta$-catenin and Axin-2 in 3T3 fibroblasts upon TGF $\beta$ activation suggesting the importance of TGF $\beta$ for the activation of canonical Wnt signaling pathway (Fig. 1B).

\subsection{Inhibition of canonical Wnt signaling pathway using Wnt/B-catenin inhibitor ICG-001 inhibited TGFB-induced mouse 3 T3 fibroblasts activation}

To investigate the functional role of canonical Wnt pathway in TGF $\beta$-induced fibroblasts activation, we used a selective Wnt/ $\beta$-catenin/CBP inhibitor ICG-001. We first confirmed the inhibition of Wnt/ $\beta$-catenin signaling by analyzing the gene expression of $\beta$-catenin and Axin-2, and found significant downregulation of these genes as confirmed by mRNA expression analysis (Fig. 1B). Thereafter, we assessed the effect of ICG-001 on TGF $\beta$-induced expression of major fibrogenic parameters e.g. collagen-I, $\alpha$-SMA (alpha smooth muscle actin, an activation marker), PDGF $\beta R$ (Platelet derived growth factor receptor beta, an activation marker) and TIMP1 (tissue inhibitor of matrix metalloproteases). We observed that following TGF $\beta$ activation, there was a significant increase in collagen-I protein expression and mRNA expression of collagen-I, $\alpha$-SMA, PDGF $\beta$ R and TIMP1 (Fig. 1C-F and Supplementary Fig. 1). Inhibition of Wnt/ $\beta$-catenin signaling pathway with ICG-001 led to the dose-dependent reduction in collagen-I protein expression (Fig. 1C) and treatment with $5 \mu \mathrm{M}$ ICG-001 led to the highly significant inhibition in the mRNA expression levels of collagen-I, $\alpha$ SMA, PDGFßR and TIMP1 (Fig. 1D-F and Supplementary Fig. 1). Periostin is a TGF $\beta$ superfamily-responsive matricellular protein, produced by fibroblasts, has been shown to be important for collagen fibrillogenesis and ECM organization [36]. We also analyzed the effects of ICG-001 on periostin expression and observed substantial upregulation of periostin in response to TGF $\beta$ which was drastically reduced 
(A)

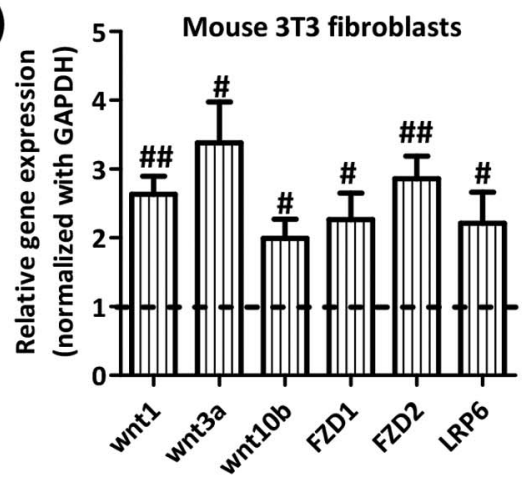

(C)

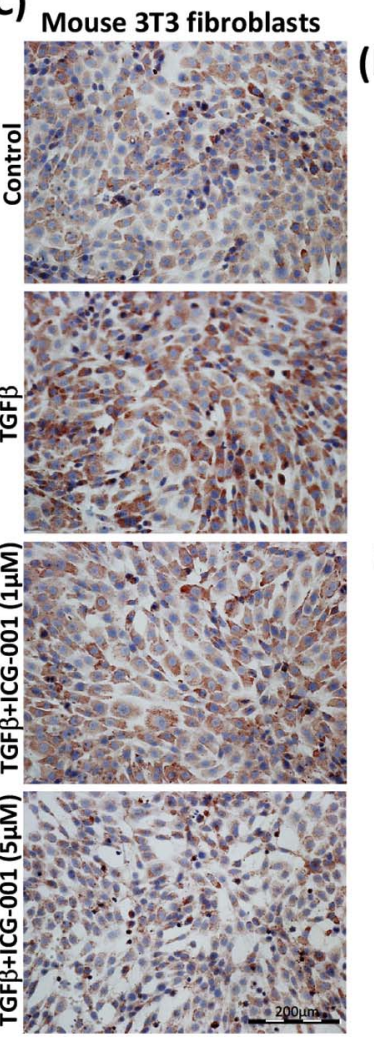

(B)

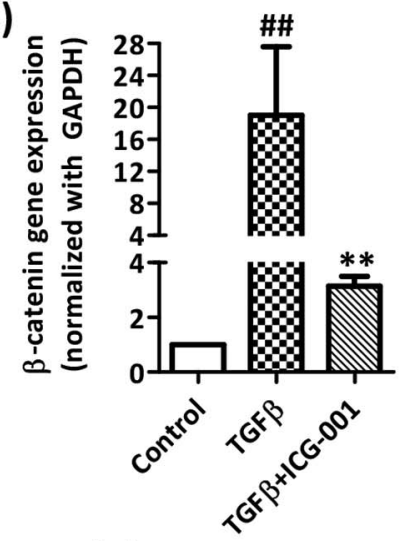

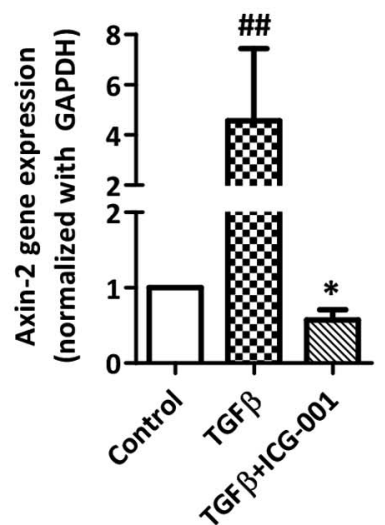

(E)

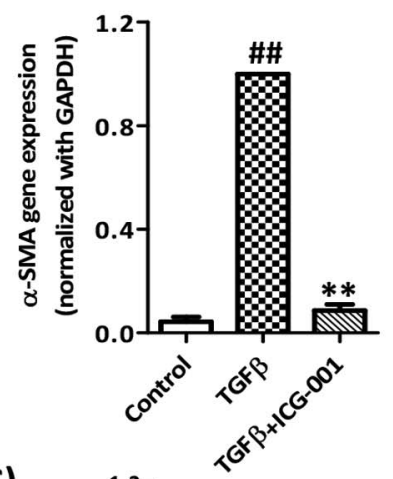

(G)

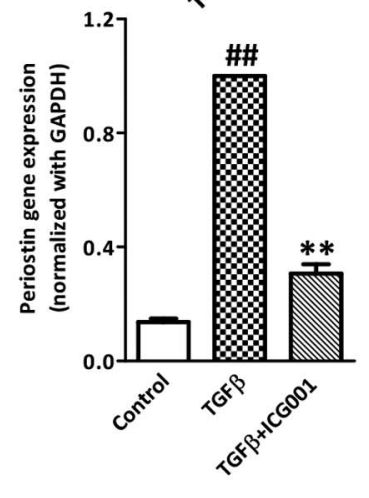

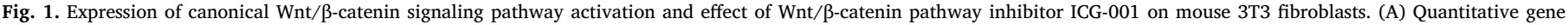

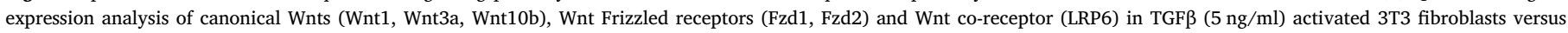

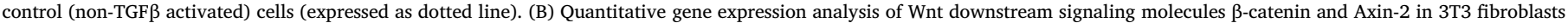

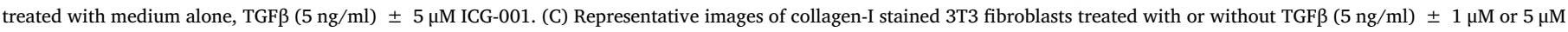

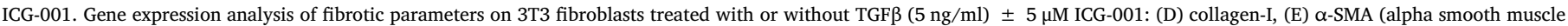

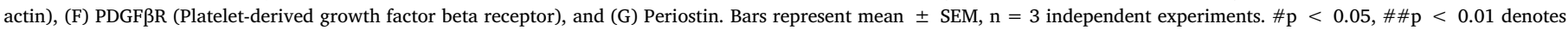
significance versus control 3T3 cells. ${ }^{*} \mathrm{p}<0.05,{ }^{* *} \mathrm{p}<0.01$ denotes significance versus TGF $\beta$-treated 3T3 cells.

following incubation with ICG-001 (Fig. 1G). No significant effect on cell viability was found at different concentrations of ICG-001, indicating no effect on cell death or proliferation (Supplementary Fig. 2).

\subsection{Canonical Wnt/ $\beta$-catenin signaling pathway inhibitor ICG-001} inhibited differentiation, migration and contractility of human LX2 cells in vitro

We further performed the studies in immortalized human hepatic stellate (LX2) cells. Following TGFß-mediated activation of LX2 cells, we observed significant upregulation of canonical Wnts (Wnt1, Wnt3a and Wnt10b), Wnt frizzled receptor FZD1 and Wnt co-receptor LRP6 (Fig. 2A) further confirming TGFß-induced activation of Wnt signaling pathway components in human HSCs. We then tested the effect of ICG001 on cell viability at $1 \mu \mathrm{M}$ and $5 \mu \mathrm{M}$. We found no significant effect on cell viability at different concentrations of ICG-001, indicating no effect on cell death or proliferation (Supplementary Fig. 3). Thereafter, we determined the effect of ICG-001 on collagen-I protein expression levels (intracellular and extracellular), and HSCs activation markers i.e. vimentin [37-39] and $\alpha$-SMA. We found that following TGF $\beta$ activation, there was a significant increase in collagen-I protein expression (both intracellular and extracellular), vimentin and $\alpha$-SMA expression (Fig. 2B-E). Additionally, inhibition of Wnt/ $\beta$-catenin signaling pathway with ICG-001 led to the dose-dependent reduction in collagenI protein expression as confirmed by immunostainings (Fig. 2B) and, inhibition of intracellular and extracellular total collagen-I protein expression (Fig. 2C-E). Furthermore, ICG-001 strongly inhibited HSCs activation/differentiation as shown by dose-dependent effect on vimentin and $\alpha$-SMA protein expression (Fig. 2B). We further examined the effect of ICG-001 on the gene expression of fibrosis-related 
(A)

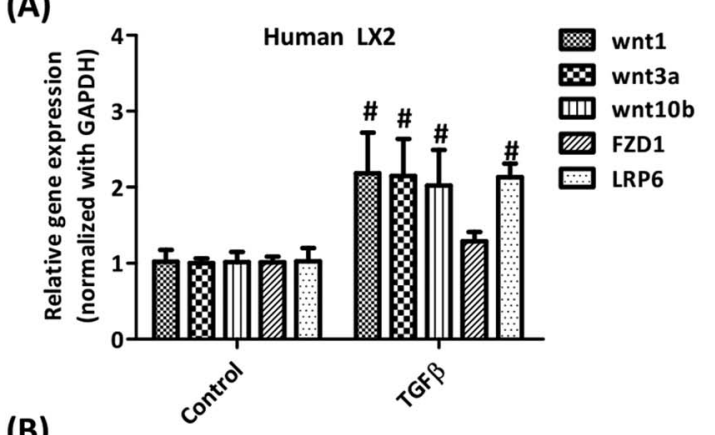

(C)

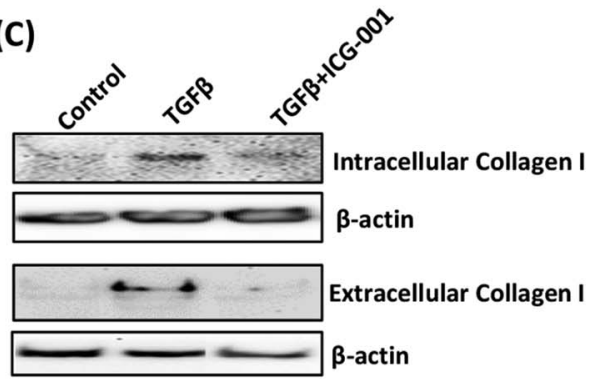

TGF $\beta+$ ICG-001 $(1 \mu \mathrm{M})$ TGF $\beta+$ ICG-001 $(5 \mu \mathrm{M})$

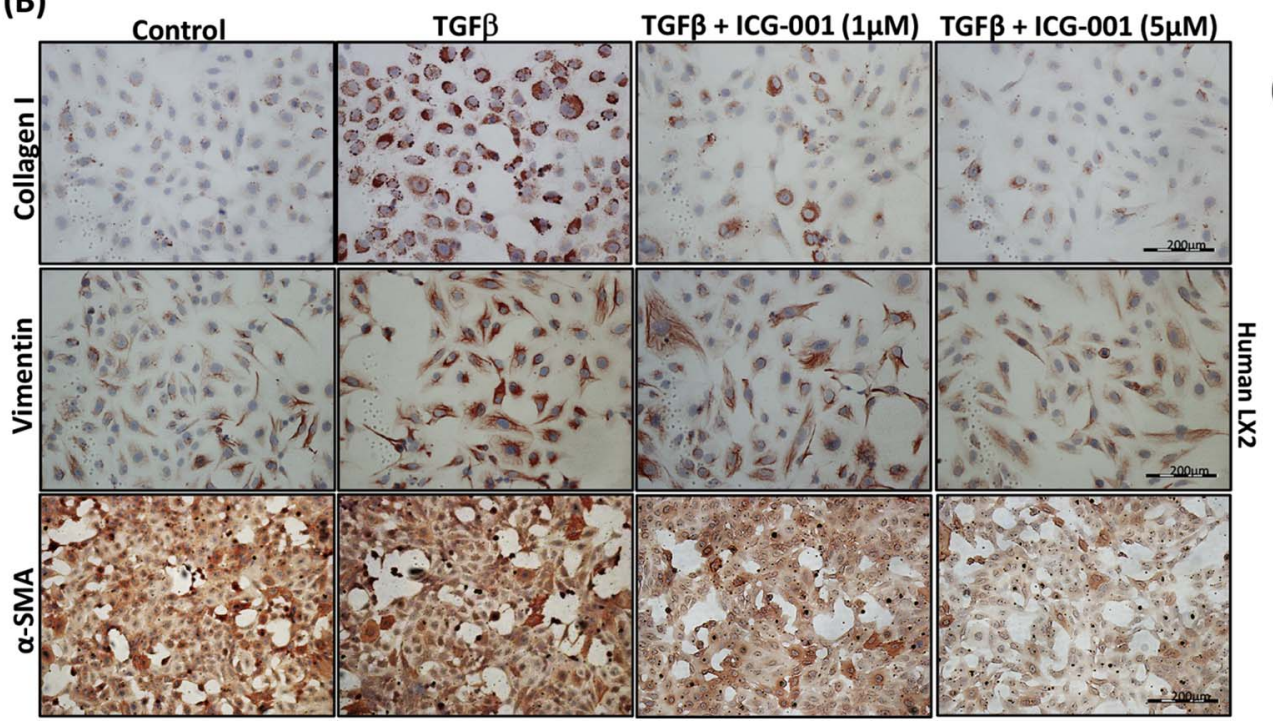

(E)
(D)

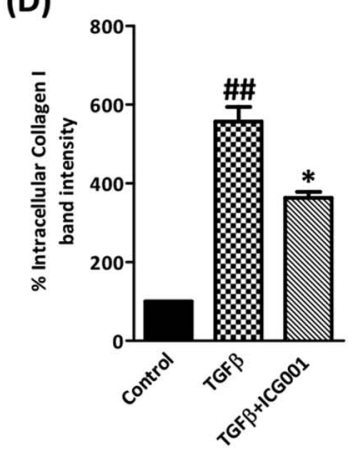

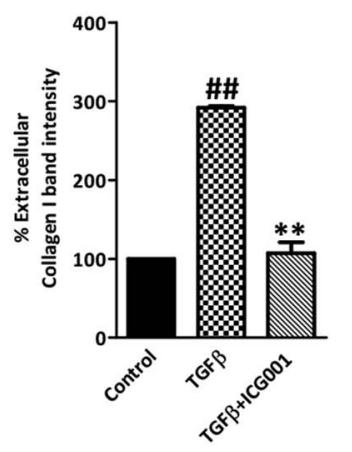

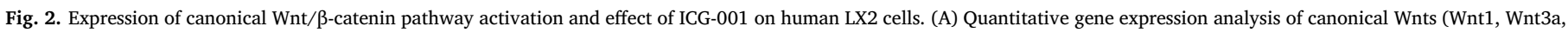

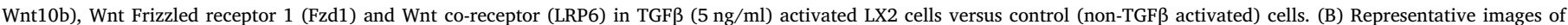

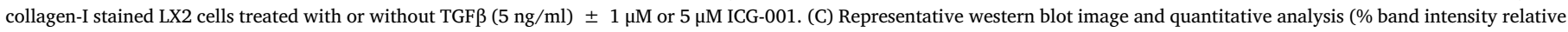

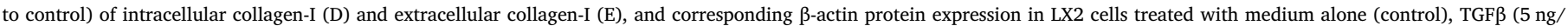

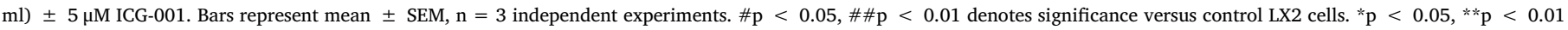
denotes significance versus TGF $\beta$-treated LX2 cells.

parameters collagen-I, vimentin, $\alpha$-SMA and PDGF $\beta R$ in LX2 cells, and observed significant dose-dependent down-regulation in the expression levels of TGF $\beta$-induced fibrogenic parameters as shown in Fig. 3A,B. To confirm that the in vitro effects are not mediated by changes in the expression levels of house-keeping gene GAPDH, we examined the variation in absolute $\mathrm{Ct}$ values of GAPDH and found that treatment with TGF $\beta$ or TGF $\beta$ + ICG-001 did not significantly influence the expression levels GAPDH expression (Supplementary Fig. 4A).

Since HSCs can migrate to the sites of tissue injury during fibrogenesis and differentiate into contractile myofibroblasts that promote liver stiffness [4], we further examined the effect of ICG-001 on migration using wound-healing assays and contractility of LX2 cells using 3D-collagen contraction assay. We found that $5 \mu \mathrm{M}$ ICG-001 significantly inhibited TGF $\beta$-induced migration of LX2 cells after $24 \mathrm{~h}$ as shown in Fig. 3C. Furthermore, ICG-001 drastically diminished TGF $\beta$ induced collagen gel contraction after $24 \mathrm{~h}, 48 \mathrm{~h}$ and $72 \mathrm{~h}$ (Fig. 3D). Maximal inhibitory effects were observed after $72 \mathrm{~h}$ of incubation as depicted in Fig. 3E. To confirm that these effects are not related to the differences in proliferation, we assessed cell proliferation using Alamar blue assay at different times of incubations both in wound healing and gel contraction and did not observe any significant differences in proliferation following ICG-001 treatment.

\subsection{Canonical Wnt/B-catenin signaling pathway inhibitor ICG-001 inhibited differentiation of primary human hepatic stellate cells in vitro}

We further extrapolated our studies in primary human hepatic stellate cells (pHSCs) to demonstrate the role and importance of Wnt/ $\beta$ catenin signaling pathway during human liver fibrosis. We therefore investigated the effect of ICG-001 on the activation of human pHSCs. Following TGF $\beta$ mediated activation, we observed significant upregulation of protein expression of collagen-I and $\alpha$-SMA (Fig. 4A,B). Inhibition of Wnt/B-catenin signaling pathway using ICG-001 resulted in highly significant inhibition in collagen-I and $\alpha$-SMA protein expression (Fig. 4A, B). We further examined the effect of ICG-001 on gene expression of collagen-I, $\alpha$-SMA and PDGF $\beta R$, and observed highly significant down-regulation in the mRNA expression levels of these parameters (Fig. 4C-E). We then also determined the effect of canonical Wnt pathway inhibition on periostin mRNA expression levels and found that ICG-001 mediated Wnt signaling pathway inhibition strongly decreased TGFß-induced periostin expression (Fig. 4F).

\subsection{Effects of ICG-001 in vivo in acute liver injury mouse model}

The effect of ICG-001 on early fibrogenesis was assessed in acute liver injury model in mice. The canonical Wnt/ $\beta$-catenin signaling pathway was found to be upregulated in the short-term $\mathrm{CCl}_{4}$-induced liver injury mouse model as depicted by the induction of Wnt/ $\beta$-catenin pathway related genes in $\mathrm{CCl}_{4}$-treated mice as compared to the olive oil 
(A)
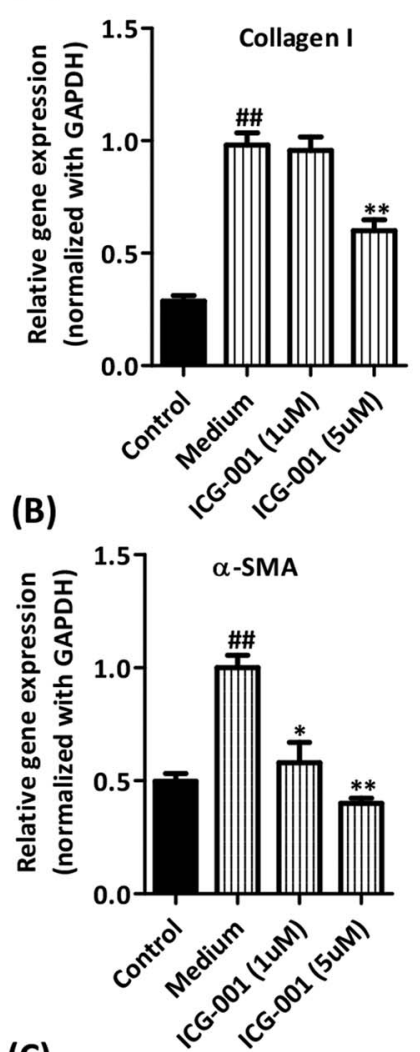

Human LX2
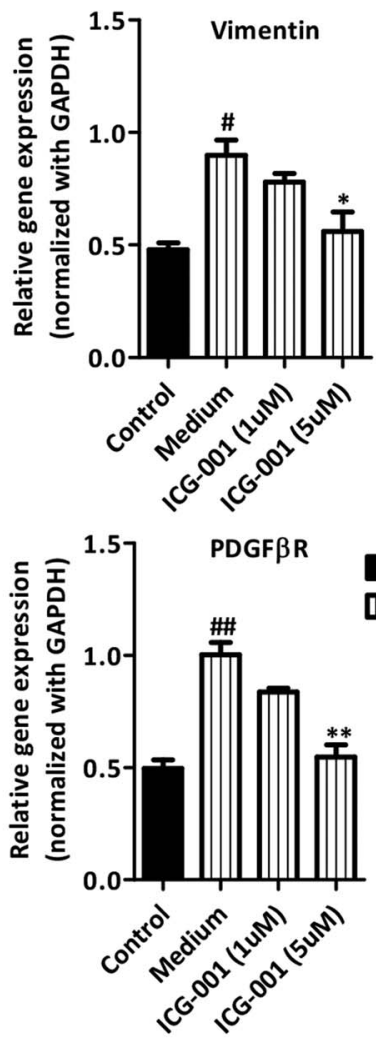

(C)

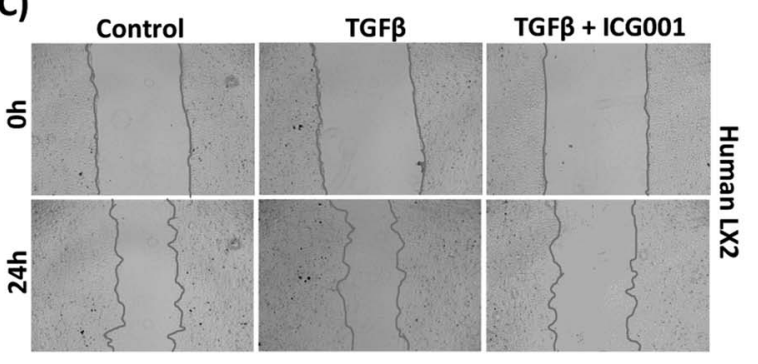

(D)

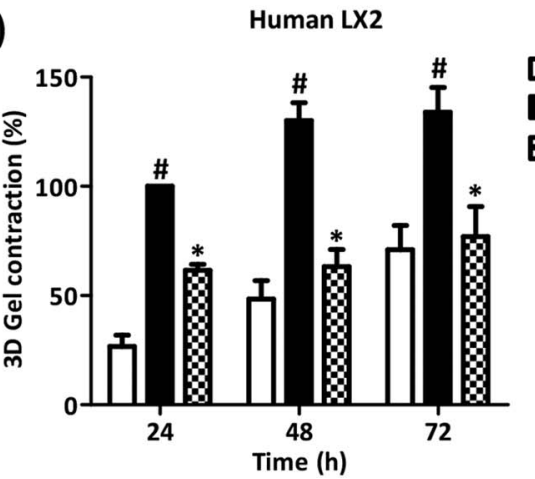

$\square$ Control

TGF $\beta$

$\mathbf{B}$ TGF $\beta+$ ICG001

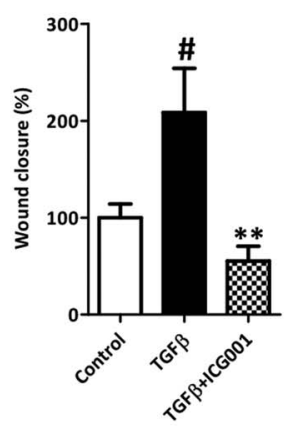

Fig. 3. Effect of ICG-001 on the gene expression of fibrotic parameters, wound healing and contractility of TGF $\beta$-activated human LX2 cells. Quantitative mRNA expression of (A) collagen-I and vimentin, and (B) $\alpha$-SMA and PDGF $\beta$ R, in LX2 cells treated with medium alone (control) or with $5 \mathrm{ng} / \mathrm{ml}$ TGF $\beta \pm 1 \mu \mathrm{M}$ or $5 \mu \mathrm{M}$ ICG001. (C) Representative images and quantitative analysis (\% wound closure) of scratch wounds made at $0 \mathrm{~h}$ and wound closure at $24 \mathrm{~h}$ as performed on control LX2, LX2 treated with TGF 3 (5 ng/ $\mathrm{ml}) \pm 5 \mu \mathrm{M}$ ICG-001. (D) Quantitative analysis (\% contraction) at different time points and (E) representative images (after $72 \mathrm{~h}$ of incubation) of 3D collagen-I gel contraction containing control LX2 cells and TGF $\beta$-activated LX2 cells treated with or without ICG-001 $(5 \mu \mathrm{M})$. Bars represent mean \pm SEM, $\mathrm{n}=3$ independent experiments. \#p $<0.05$, \#\#p $<0.01$ denotes significance versus control LX2 cells. *p $<0.05,{ }^{* *} \mathrm{p}<0.01$ denotes significance versus TGF $\beta$-treated LX2 cells.

\section{(E)}

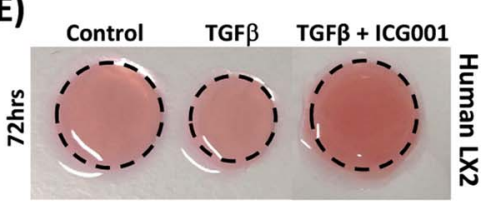

treated control mice (Fig. 5A, B). We observed significant upregulation of Wnt proteins (Wnt1, Wnt3a and Wnt10b), Wnt frizzled receptors FZD1 and FZD2 and Wnt co-receptor LRP6 in $\mathrm{CCl}_{4}$-treated mice versus olive oil treated control mice. In vivo activation of canonical Wnt/ $\beta$ catenin signaling pathway was confirmed by upregulation of $\beta$-catenin and Axin-2 gene expression and in vivo inhibition with ICG-001 was confirmed by complete down-regulation of $\beta$-catenin and Axin- 2 expression as depicted in Fig. 5B.

Interestingly, post-disease intraperitoneal treatment with ICG-001 $(5 \mathrm{mg} / \mathrm{kg}$ ) induced a strong resolution of early fibrogenesis as shown by the significant decrease in collagen-I protein, total liver collagen content (as measured by hydroxyproline assay) and mRNA expression levels in ICG-001 treated mice as compared to $\mathrm{CCl}_{4}$-vehicle mice (Fig. 5C-F). Furthermore, we investigated the effects of ICG-001 on other crucial ECM proteins e.g. cadherin 11 [40], fibronectin, and ITGA5 (fibronectin receptor) [41-43], and observed strong inhibition in the expression of these parameters following ICG-001 treatment as depicted in Fig. 5G-I. Furthermore, ECM regulatory protein, tissue inhibitor of metalloproteinases 1 (TIMP1) was highly reduced following ICG-001 treatment (Fig. 5J). 


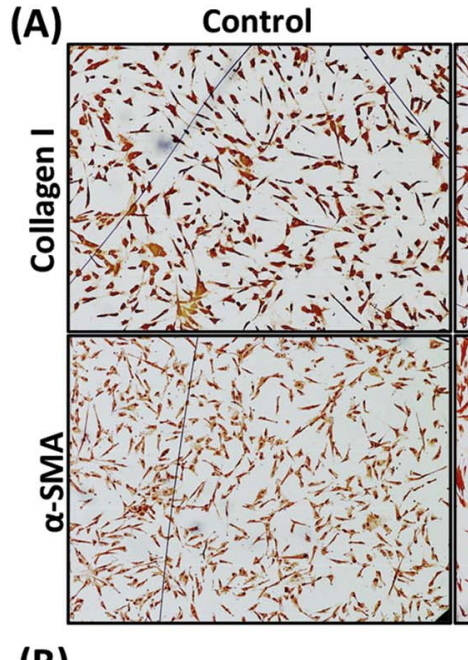

(B)
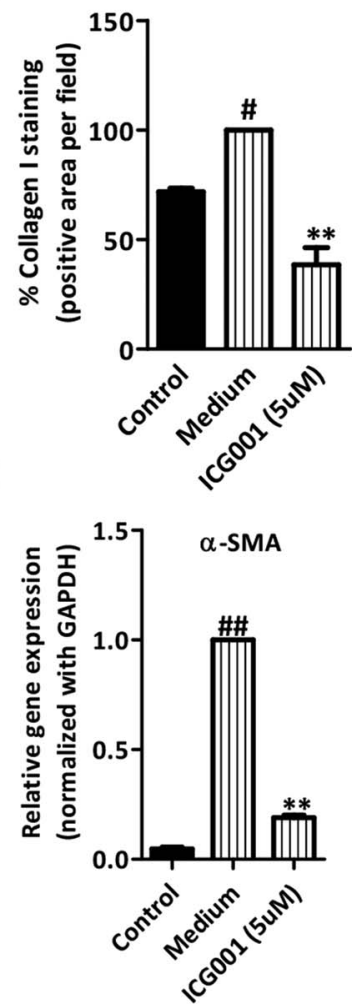

TGF $\beta$

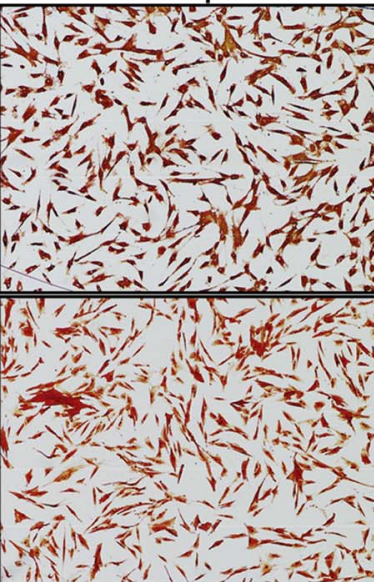

TGF $\beta+$ ICG-001(5 $\mu \mathrm{M})$

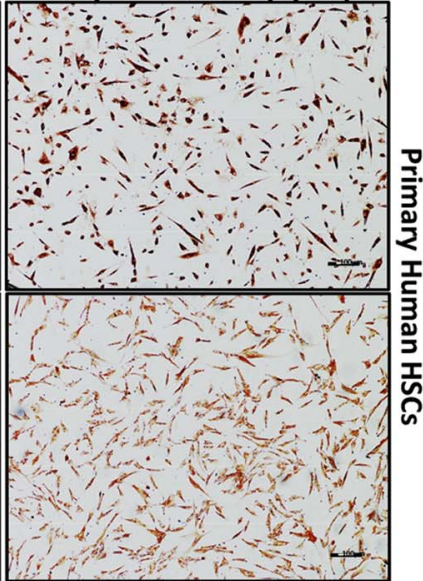

Fig. 4. Effect of ICG-001 on activation of TGF $\beta$ activated primary human hepatic stellate cells (pHSCs). (A) Representative images and (B) Quantitative histological analysis of collagen-I and $\alpha$-SMA stained pHSCs treated with or without TGF $\beta \quad(5 \mathrm{ng} / \mathrm{ml}) \pm 5 \mu \mathrm{M} \quad$ ICG-001. Quantitative gene expression of fibrotic parameters: (C) collagen-I, (D) $\alpha$-SMA, (E) PDGF $\beta R$ and (F) Periostin in pHSCs treated with or without TGF $\beta(5 \mathrm{ng} / \mathrm{ml}) \pm 5 \mu \mathrm{M}$ ICG-001. Bars represent mean \pm SEM, $\mathrm{n}=3$ independent experiments. \#\#p $<0.01$ denotes significance versus control cells; ${ }^{*} \mathrm{p}<0.05$, ${ }^{* *} \mathrm{p}<0.01$ denotes significance versus TGF $\beta$-treated pHSCs.

(D) Primary Human HSCs

(E)
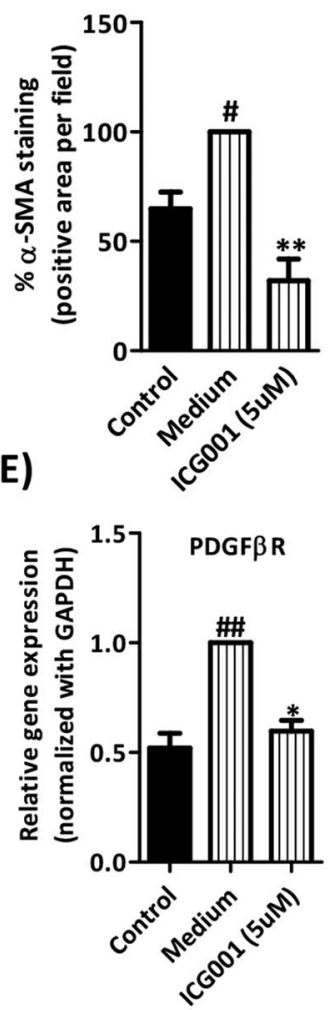

(C)

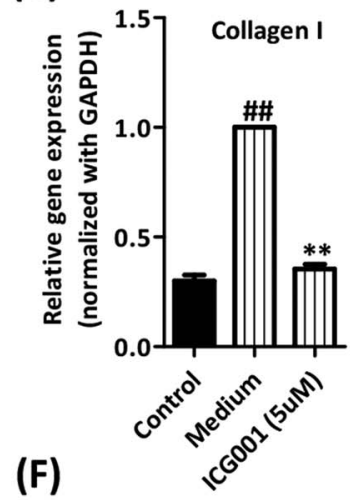

(F)
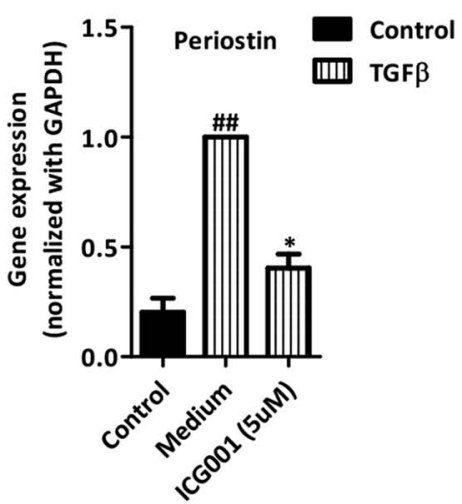

We further assessed the effects of ICG-001 on HSCs activation in vivo. In acute liver fibrogenesis mouse model, we observed significant activation of HSCs in fibrotic mice as compared to olive-oil treated normal mice as confirmed by $\alpha$-SMA and desmin protein and gene expression levels (Fig. 6A-C). ICG-001 treatment led to the highly significant reduction in protein and gene expression levels of $\alpha$-SMA and desmin (Fig. 6A-C). Altogether, these results suggests that Wnt/ $\beta$-catenin pathway inhibition using ICG-001 results in the highly significant downregulation of ECM accumulation, HSCs activation and hence amelioration of hepatic fibrogenesis.

\subsection{Canonical Wnt/ $\beta$-catenin signaling pathway inhibition attenuates angiogenesis in acute liver injury mouse model}

We further investigated the effect of ICG-001 on intrahepatic angiogenesis in vivo. We found that ICG-001 treatment induced a significant reduction in the $\mathrm{CCl}_{4}$-induced expression of major pan- endothelial cell markers CD31 and CD34 (Fig. 6D-E). Expression of angiogenesis stimulating factor VEGF (vascular endothelial growth factor) was also found to be highly reduced following ICG-001 treatment (Fig. 6F). These anti-angiogenic effects could be partially mediated by inhibition of Notch signaling pathway as confirmed by inhibition of mRNA expression levels of Hes1 (Notch downstream pathway signaling molecule) and SOX9 (sex determining region Y)-HMG box 9 (Fig. 6G-H).

3.7. Canonical Wnt/ $\beta$-catenin signaling pathway inhibition attenuates liver inflammation in acute liver injury mouse model

To study whether the effects of ICG-001 on fibrosis were also related to the changes in the macrophages, we investigated intrahepatic inflammation, macrophage infiltration, the status of M1 and M2 macrophages in the control (normal), fibrotic and ICG-001 treated livers. We first assessed total hepatic macrophage population and found that F4/ 
(A)

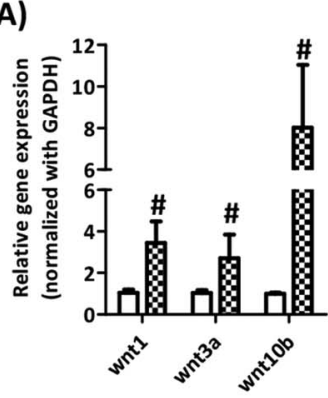

(C)

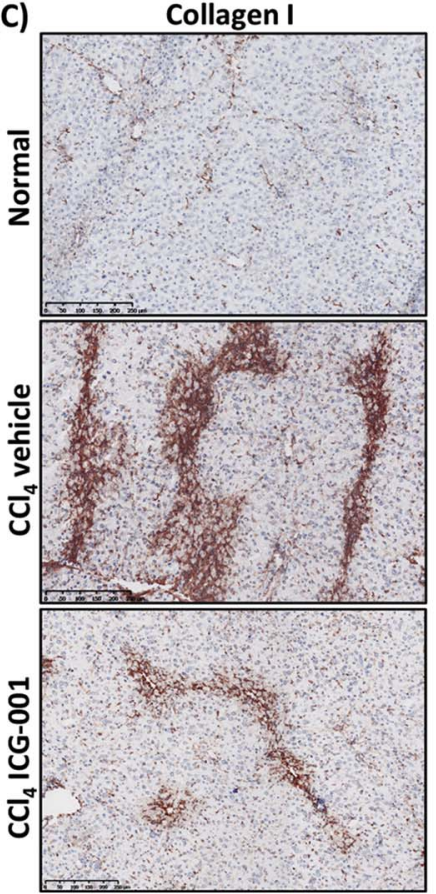

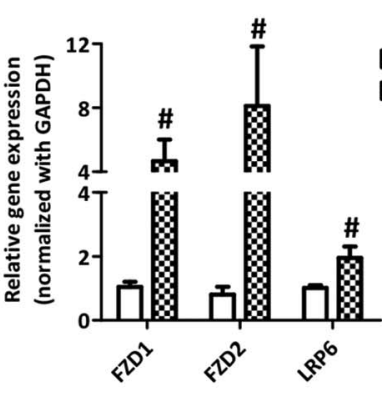

(D)

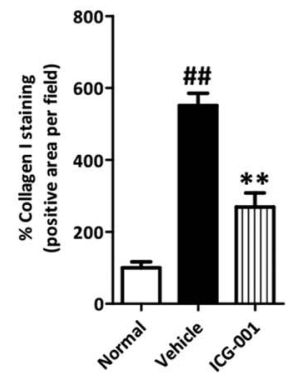

(E)

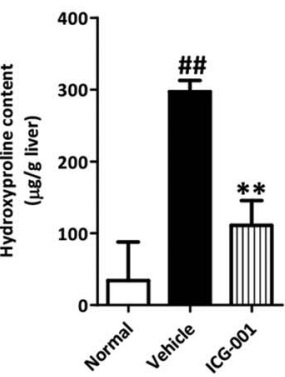

(H)

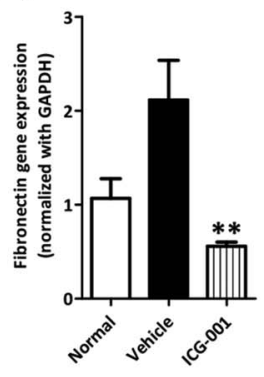

(B)

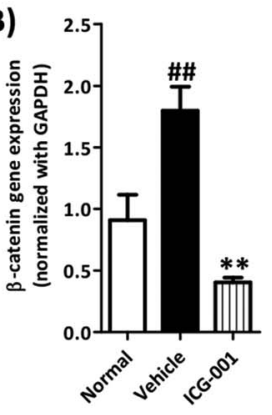

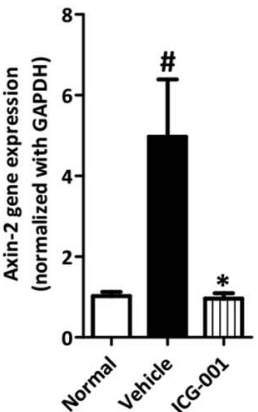

(F)

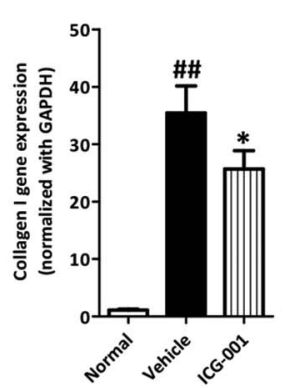

(I)

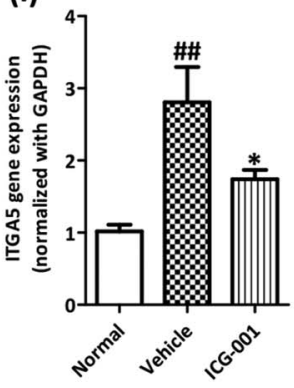

(J)

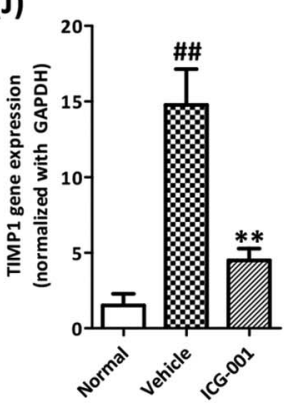

(G)

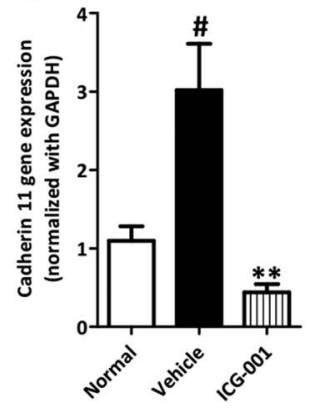

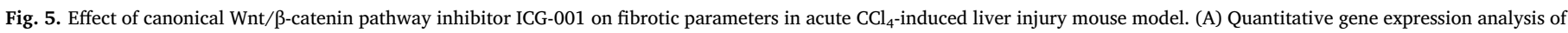

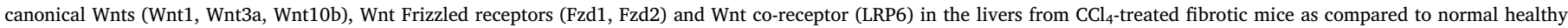

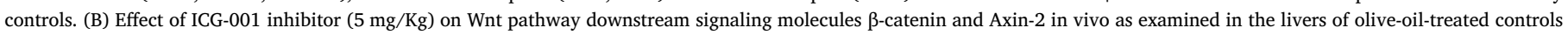

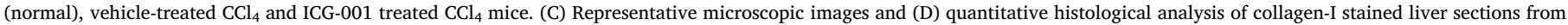

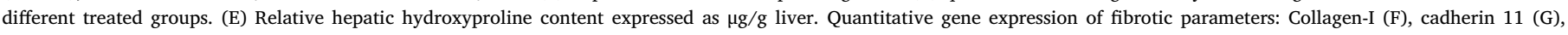

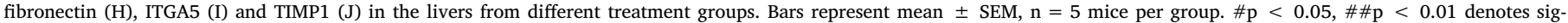
nificance versus olive-oil treated control group; ${ }^{*} \mathrm{p}<0.05$, ${ }^{* *} \mathrm{p}<0.01$ denotes significance versus $\mathrm{CCl}_{4}$-treated vehicle group.

$80+$ macrophages were significantly increased after $\mathrm{CCl}_{4}$ administration and was highly significantly attenuated after ICG-001 treatment as shown in Fig. 7A. We examined plasma ALT levels and observed highly significant downregulation in ALT levels following treatment with ICG001 suggesting attenuation of intrahepatic inflammation (Fig. 7B). Thereafter, we assessed mRNA expression levels of major inflammatory cytokines e.g. macrophage chemotactic protein 1, MCP1 (or C-C Motif Chemokine Ligand 2, CCL2) and TNFa, and found that after ICG-001 treatment, there is significant reduction in CCL2 and TNFa expression (Fig. 7C, D). As shown in Fig. 7E, F, we found that ICG-001 suppressed M1 macrophage polarization as confirmed by quantitative PCR for selective M1 (NOS2) but induced M2 macrophage polarization as confirmed by M2 (Arginase I) marker, illustrating the down-regulation of M1 macrophages while upregulation of M2 macrophages. The M1 and M2 skewing was further confirmed with western blotting using MHC-II (an inflammatory marker) but induced M2 macrophage polarization, as confirmed by western blotting using YM1 (M2-specific marker) (Fig. 7G, H).

To confirm that the in vivo effects are not mediated by changes in the expression levels of house-keeping gene GAPDH, we examined the variation in absolute $\mathrm{Ct}$ values of GAPDH and found that treatment with
TGF $\beta$ or TGF $\beta$ + ICG-001 did not significantly influence the expression levels GAPDH expression (Supplementary Fig. 4B).

\subsection{Inhibition of canonical WNT signaling pathway by ICG-001 inhibits expression of stromal derived factor SDF1 $\alpha / C X C L 12$}

To understand the mechanism or factors involved in ICG-001 driven inhibition of HSCs, we performed cytokine profile array using conditioned medium derived from primary human HSCs (Fig. 8A). Remarkably, we found that ICG-001 strongly inhibited Chemokine (C-X-C motif) ligand 1 (CXCL1) and Chemokine (C-X-C motif) ligand 12 (CXCL12) protein expression (Fig. 8A, B). CXCL12, also known as stromal cell-derived factor 1 (SDF-1), expressed by fibroblasts, has been shown to act both in autocrine and paracrine fashion. We thereafter assessed the gene expression of CXCL12 after TGF $\beta$ activation in 3T3 fibroblasts, human LX2 cells and primary human HSCs (Fig. 8C-E). We found that TGF $\beta$-mediated activation consistently upregulated CXCL12 expression in fibroblasts and HSCs as shown in Fig. 8C-E. Following inhibition of Wnt/ $\beta$-catenin pathway using ICG-001, we observed complete inhibition of TGF $\beta$-induced CXCL12 levels (Fig. 8C-E) suggesting regulation of CXCL12 by Wnt/ $\beta$-catenin signaling pathway. We 
(A)
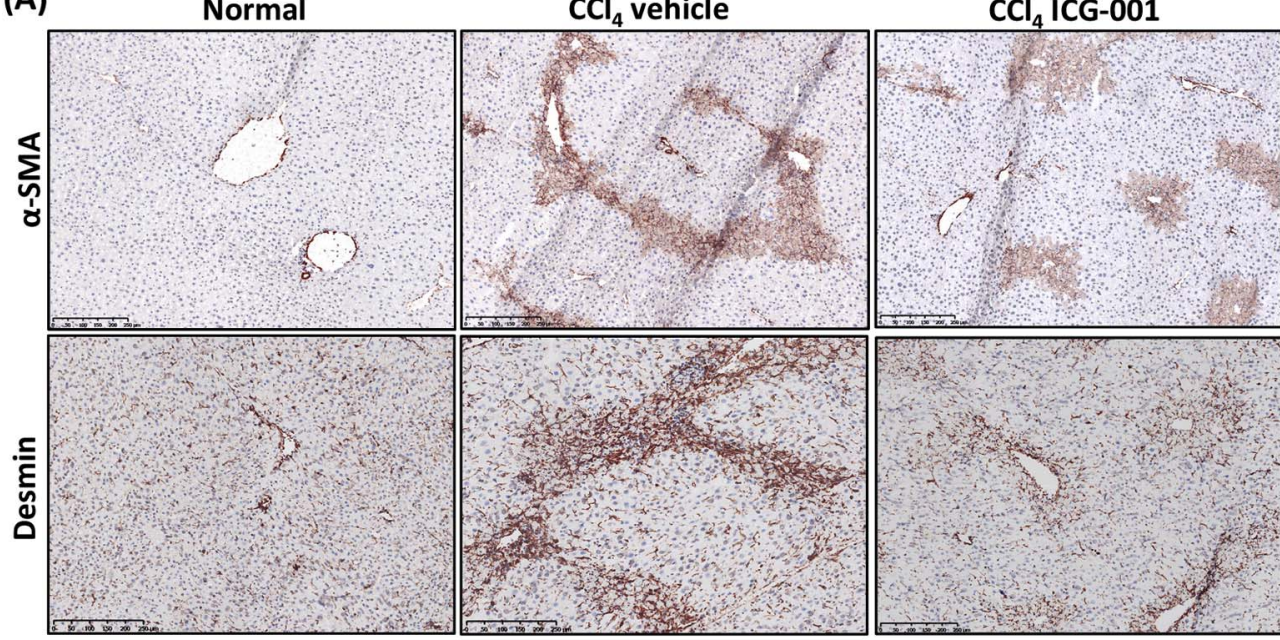

(B)

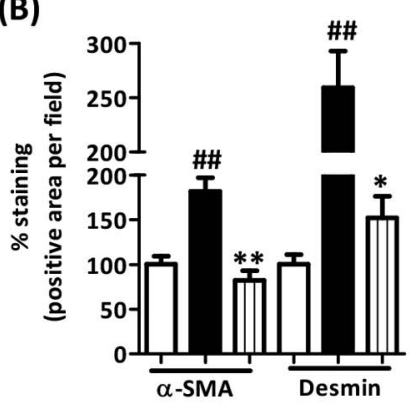

(C)

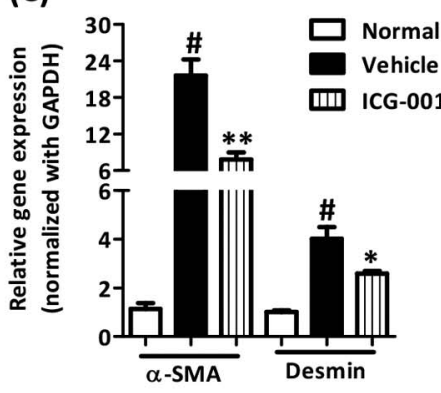

(E)

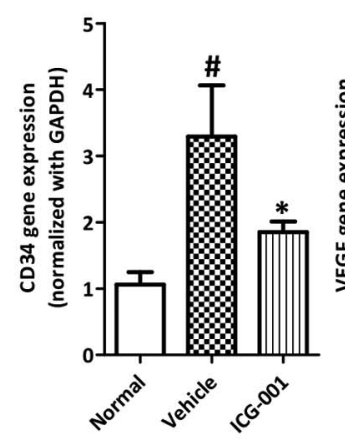

(F)

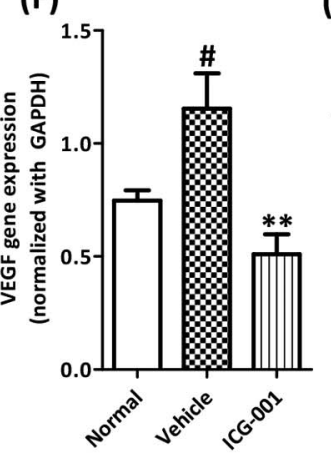

(G)

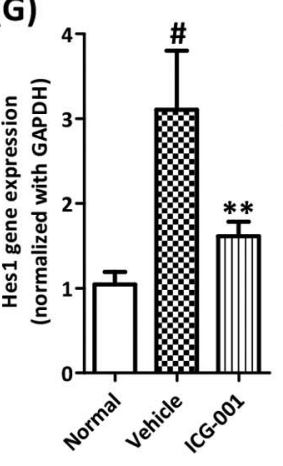

(D)

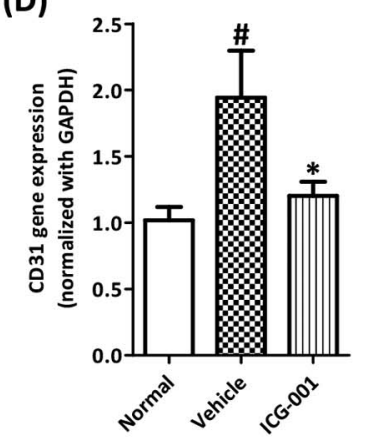

(H)

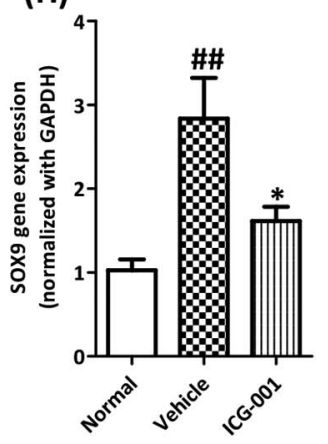

Fig. 6. Effect of canonical Wnt/ $\beta$-catenin pathway inhibitor ICG-001 on HSC activation and angiogenesis in acute $\mathrm{CCl}_{4}$-induced liver injury mouse model. (A) Representative photomicrographs and (B) quantitative histological analysis of $\alpha$-SMA and Desmin stained liver sections from normal (olive-oil treated control), vehicle and ICG-001 treated $\mathrm{CCl}_{4}$ mice. Quantitative mRNA analysis (normalized with GAPDH) of (C) HSC markers ( $\alpha$-SMA and desmin), angiogenesis markers: CD31 (D), CD34 (E) and VEGF (F), and Notch signaling pathway molecules: Hes1 (Notch downstream pathway signaling molecule) (G) and SOX9 (sex determining region $\mathrm{Y}$ )-HMG box $9(\mathrm{H})$ in the livers of different treated groups. Bars represent mean \pm SEM, $\quad \mathrm{n}=5 . \quad \# \mathrm{p}<0.05 \quad$ and \#\# $\mathrm{p}<0.01$ denotes significance versus oliveoil treated control group; * $\mathrm{p}<0.05$, ** $\mathrm{p}<0.01$ denotes significance versus $\mathrm{CCl}_{4}-$ treated vehicle group. also determined the in vivo intrahepatic expression levels of CXCR4 and CXCL12 and found significant increase in CXCR4 (about 7 fold, $\mathrm{p}<0.01$ ) and CXCL12 (about 1,5 fold, $\mathrm{p}<0.01$ ). Previous study has also reported the similar observation where CXCR4 expression was highly significantly increased as compared to CXCL12 transcript levels [44]. We then determined the effect of in vivo canonical Wnt pathway inhibition on the chemokine system CXCL12/CXCR4 and found that ICG-001 mediated Wnt signaling inhibition strongly decreased in vivoinduced CXCR4 and CXCL12 expression (Fig. 8F, G) further reinforcing the CXCL12 role in Wnt/ $\beta$-catenin signaling pathway.

\subsection{ICG-001 inhibited fibroblasts-driven angiogenesis, macrophage migration and inflammation in vitro via CXCL12-mediated paracrine signaling}

Fibroblasts (or HSCs) plays multifactorial role in liver fibrosis via paracrine signaling pathways by releasing growth factors, thereby significantly inducing angiogenesis and inflammation [4-6]. Additionally, the positive feedback loop between fibroblasts activation, inflammation and angiogenesis further aggravate fibrosis [3,5]. Here, we hypothesized that ICG-001 inhibitory effects on 3T3 fibroblasts induces paracrine inhibitory effects on angiogenesis and macrophage migration and polarization via CXCL12. To address this hypothesis, we studied the paracrine effect of ICG-001 treated 3T3 fibroblasts on endothelial cells and macrophages. Based on previous in vitro and in vivo results, we hypothesized that CXCL12 derived from fibroblasts induces angiogenesis and macrophage activation and migration, and inhibition of Wnt/ $\beta$-catenin signaling pathway using ICG-001 inhibits CXCL12 secretion, and therefore inhibits angiogenesis i.e. endothelial cells tube formation and activation, and macrophage infiltration and activation i.e. inflammation.

To model fibroblasts-induced angiogenesis, we activated 3T3 fibroblasts with TGF $\beta$ with or without $5 \mu \mathrm{M}$ ICG-001. Thereafter, we washed fibroblasts to remove the initial stimuli and then cultured them in a fresh medium. After $24 \mathrm{~h}$, conditioned medium was added to H5V endothelial cells and tube formation assay was performed. Conditioned media derived from control fibroblasts and TGF $\beta$-stimulated fibroblasts enhanced endothelial tube formation as compared to that of control 
(A)

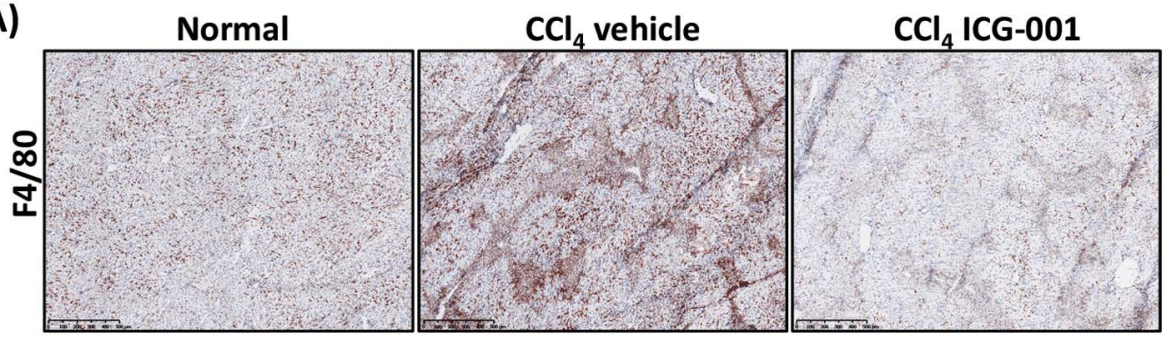

(B)

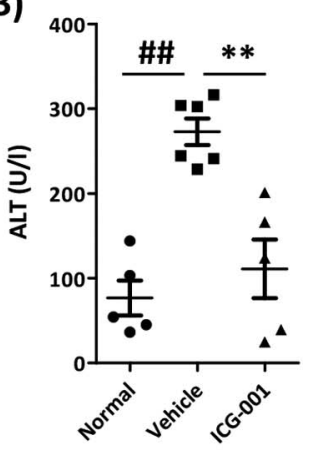

(E)

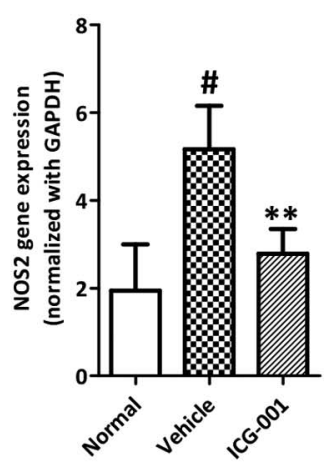

(c)

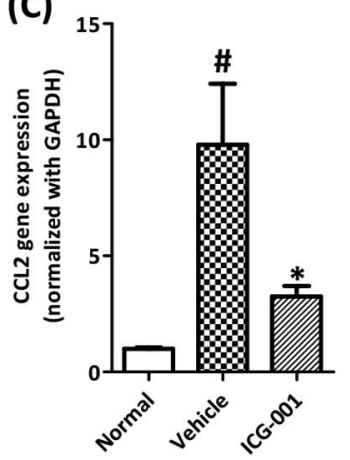

(F)

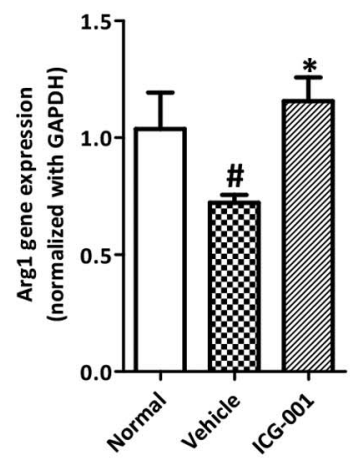

(D)

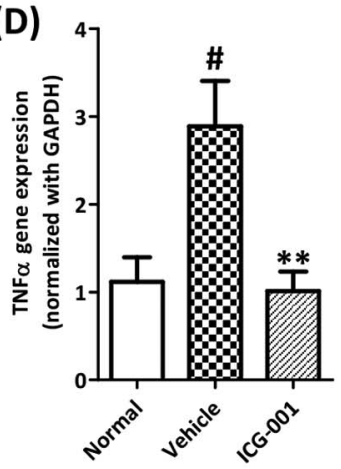

(G) Normal $\mathrm{CCl}_{4}$ ICG001

(H) Normal $\mathrm{CCl}_{4}$ BIBF1120
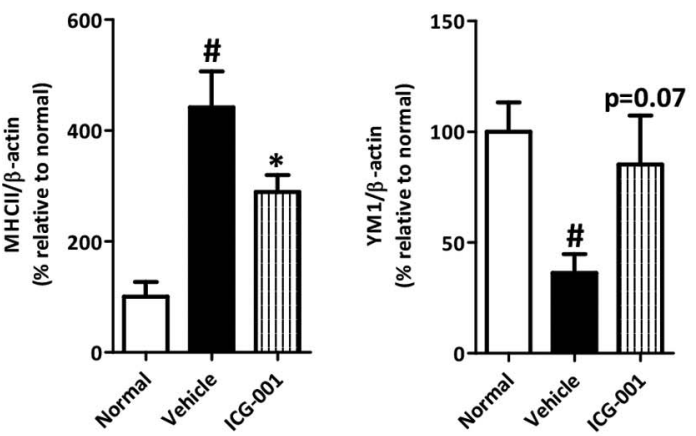

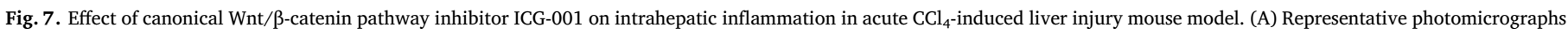

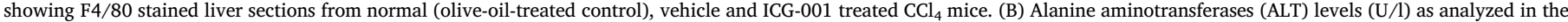

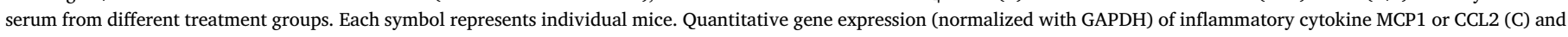

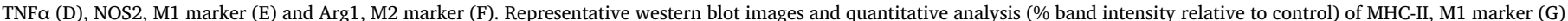

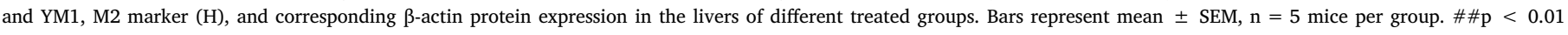
denotes significance versus olive-oil treated control group.

(non-cell treated) medium indicating that paracrine stimulus probably CXCL12 from fibroblasts and TGF $\beta$-activated fibroblasts induces endothelial cells activation and angiogenesis (Fig. 9A-C). Interestingly, medium derived from 3T3 fibroblasts after treatment with ICG-001 significantly inhibited the TGF $\beta$-induced tube formation suggesting that inhibition of secretory factors i.e. CXCL12 from ICG-001 treated fibroblasts inhibited fibroblasts-induced angiogenesis (Fig. 9A, B). To further demonstrate that CXCL12 indeed is involved in this process, we performed tube formation assay in the presence of CXCL12 and found significant increase in tube formation as can be seen in Fig. 9A, B. In addition, treatment with CXCL12 antibody together with TGF $\beta$-conditioned medium inhibited tube formation further reinforcing the direct paracrine role of CXCL12 in angiogenesis (Fig. 9A, B). We further analyzed the NOS3 (eNOS or nitric oxide synthase 3, endothelial marker) expression following incubation with conditioned medium and observed that conditioned medium derived from TGF $\beta$-treated 3T3 fibroblasts and CXCL12 induced significant upregulation in NOS3 expression which was strongly inhibited following incubation with conditioned medium derived from ICG-001 treated 3T3 fibroblasts (Fig. 9C).

Furthermore, we developed in vitro model to study fibroblasts- induced macrophage migration and activation. We added the conditioned medium from control 3T3 cells, TGF $\beta$-treated 3T3 or TGF $\beta$ + ICG-001 treated 3T3 in the lower chamber/insert and macrophages in the upper chamber to study the effect on macrophage migration through the membrane. We observed that conditioned medium from control 3T3 fibroblasts induced macrophage migration as compared to control (non-cell treated) medium suggesting chemotactic factors secreted by 3T3 fibroblasts (Fig. 9D, E). This macrophage migration was significantly enhanced in response to conditioned medium derived from TGF $\beta$-treated 3T3 fibroblasts and was strongly inhibited following incubation with conditioned medium derived from ICG-001 treated 3T3 fibroblasts (Fig. 9D, E). We further analyzed the expression levels of NOS2 (iNOS or nitric oxide synthase 2, M1 inflammatory macrophage marker) and IL-1 $\beta$ (inflammation marker). We observed that conditioned medium derived from TGF $\beta$-treated 3T3 fibroblasts induced significant upregulation in IL- $1 \beta$ expression as compared to conditioned medium derived from 3T3 fibroblasts. This increase in expression levels were strongly inhibited following incubation with conditioned medium derived from TGF $\beta$ + ICG-001 treated 3T3 fibroblasts (Fig. 9F). To further demonstrate the role of CXCL12 in macrophage chemotactic process, we performed chemotaxis in the 
(A)

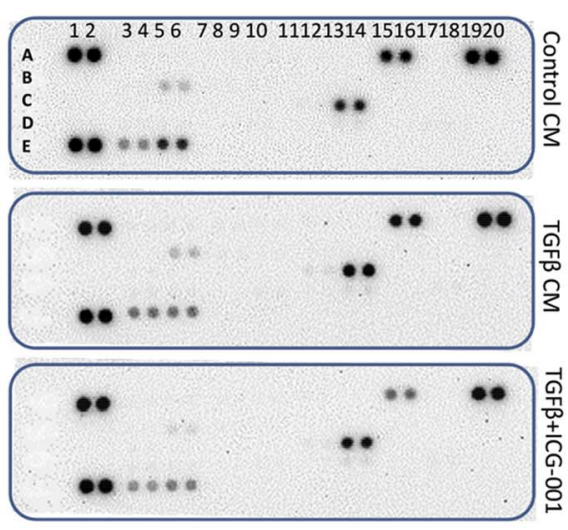

(C)

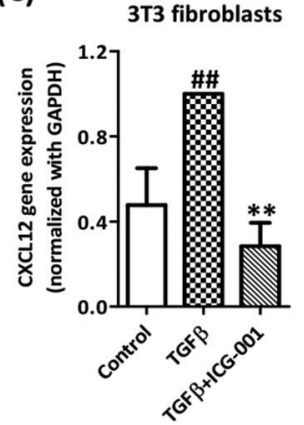

(D) LX2 cells

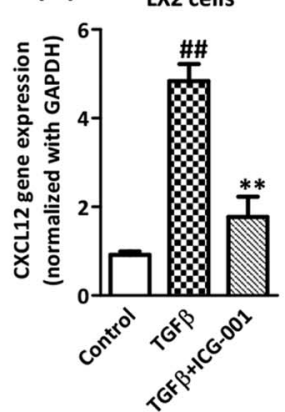

(B)

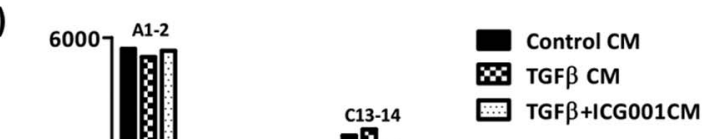

(E)

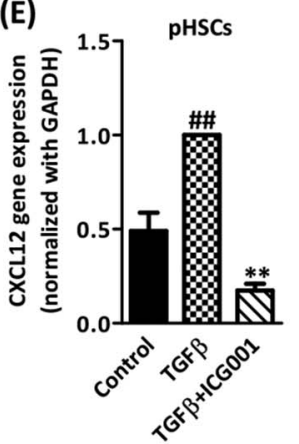

(F)

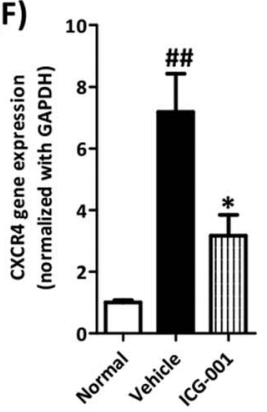

(G)

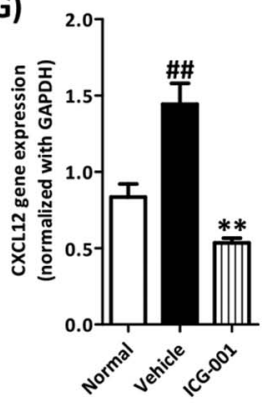

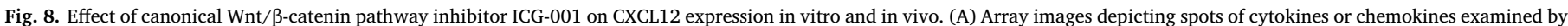

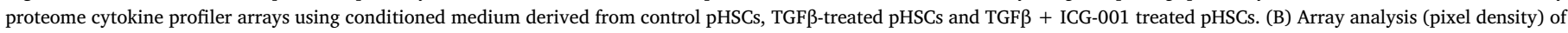

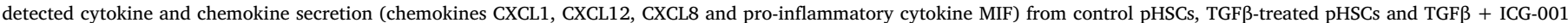

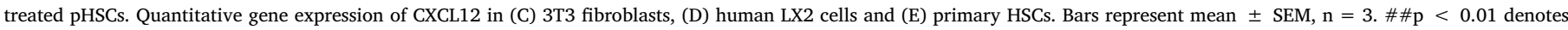

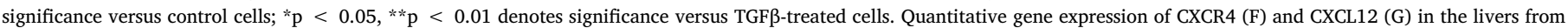

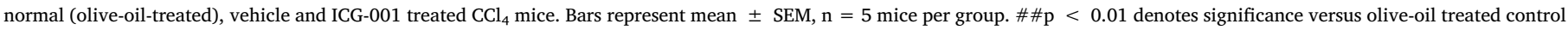
group.

presence of CXCL12 and found significant increase in migration as compared to control as shown in Fig. 9D, E. Furthermore, treatment with CXCL12 antibody prior to addition of TGF $\beta$-conditioned medium completely abrogated macrophage migration further suggesting the direct paracrine function of CXCL12 in macrophage migration and intrahepatic inflammation (Fig. 9D, E). We further analyzed the IL-1 $\beta$ expression following incubation with conditioned medium and CXCL12, and observed that conditioned medium derived from TGF $\beta$ treated 3T3 fibroblasts and CXCL12 induced significant upregulation in IL-1 $\beta$ expression (Fig. 9F). Interestingly, conditioned medium derived from ICG-001 treated 3T3 fibroblasts strongly inhibited IL-1 $\beta$ expression (Fig. 9F).

\subsection{ICG-001 inhibited primary human HSCs-driven LSECs and Kupffer cells activation in vitro}

We further extrapolated the conditioned medium studies using primary human HSCs, primary LSECs and primary human kupffer cells to reinforce the findings observed with 3T3 conditioned medium. We incubated hepatic kupffer cells with conditioned medium obtained from pHSCs incubated with medium, TGF $\beta$ and TGF $\beta$ + ICG-001. We observed that TGF $\beta$-incubated pHSCs conditioned medium significantly upregulated NOS2 and TNF $\alpha$ expression in primary human kupffer cells suggesting activation of primary human liver-derived macrophages (Fig. 9G). This activation was abrogated following incubation with conditioned medium derived from ICG-001-treated pHSCs (Fig. 9G). Since it has been shown that LSECs are required to maintain HSCs quiescence and during liver fibrosis, LSECs secrete fibronectin, and become highly pro-inflammatory and are a critical component of intrahepatic inflammation $[6,7,45]$, we analyzed HSCs-mediated effect on primary LSECs. We observed that following incubation with conditioned medium derived from TGF $\beta$-activated pHSCs led to increased expression of fibronectin (Fig. 9H). This increase was inhibited by incubation with conditioned medium obtained from ICG-001-treated pHSCs suggesting that the soluble factors (i.e. CXCL12) produced by pHSCs stimulate both kupffer cells and LSECs and these factors or effects of pHSCs-derived factors were inhibited by ICG-001.

\section{Discussion}

In this study, we have presented the systematic analysis of the expression of canonical Wnts, Wnt (co) receptors and $\beta$-catenin in TGF $\beta$ activated fibrogenic hepatic stellate cells and in early liver fibrosis. We demonstrate that selective inhibition of canonical Wnt/ $\beta$-catenin using ICG-001 significantly attenuated TGF $\beta$-activated fibroblasts and HSC activation, collagen deposition, HSC contractility and migration in vitro. In vivo in $\mathrm{CCl}_{4}$-induced early liver fibrosis in mice, canonical Wnt pathway inhibition significantly inhibited ECM deposition and HSC differentiation. Remarkably, ICG-001 suppressed intrahepatic inflammation, macrophage polarization and angiogenesis. To further understand the underlying mechanism or paracrine factors involved in inflammation and angiogenesis, we performed conditioned medium studies and showed that HSCs activation induces Wnt-driven endogenous and exogenous expression of stromal factor CXCL12 or SDF1 $\alpha$, which in autocrine manner stimulates HSCs activation and differentiation, and in paracrine manner induces macrophage activation and inflammation, and stimulates endothelial cells activation and angiogenesis. Following Wnt pathway inhibition, CXCL12 expression is 
(A)

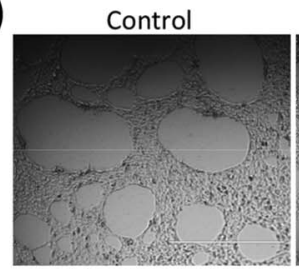

TGF $\beta$ + ICG-001 CM

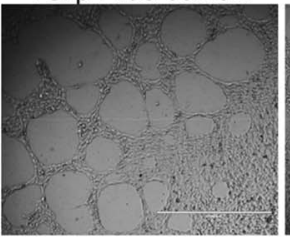

(D)

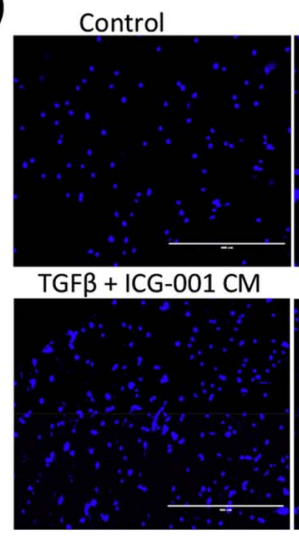

Control CM

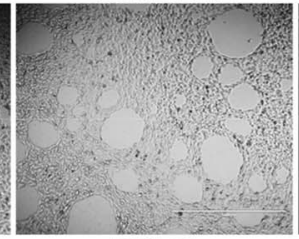

CXCL12

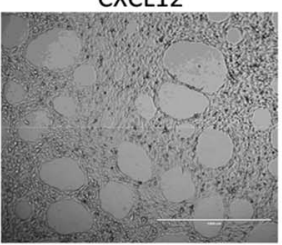

Control CM

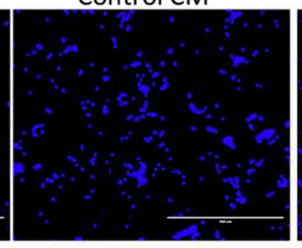

CXCL12

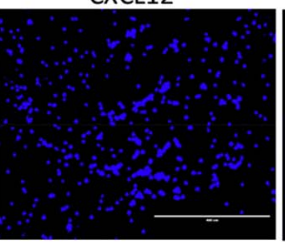

TGF $\beta$ CM

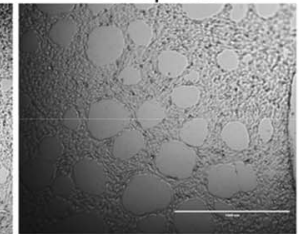

TGF $B C M+C X C L 12 A b$

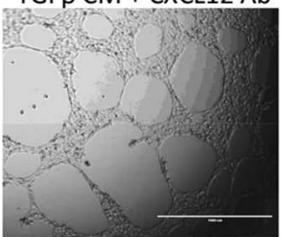

TGF $\beta$ CM
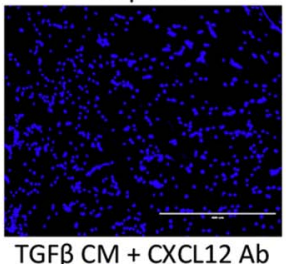

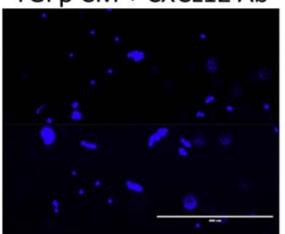

(B)
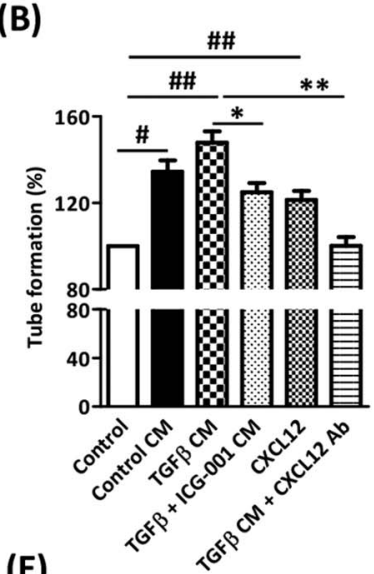

(E)

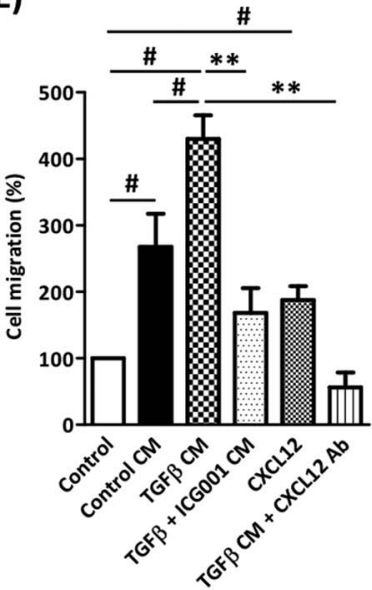

(H)

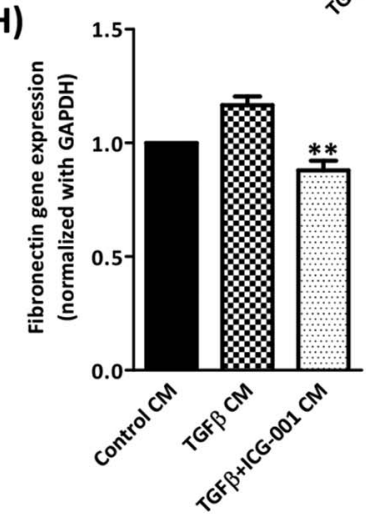

(C)

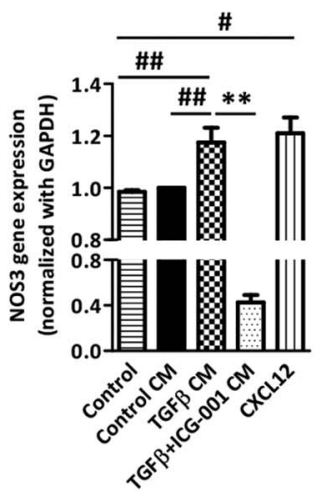

(F)

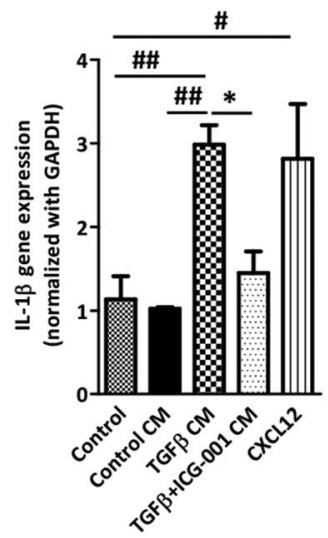

(G)

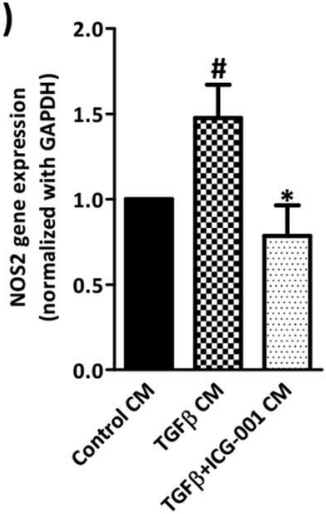

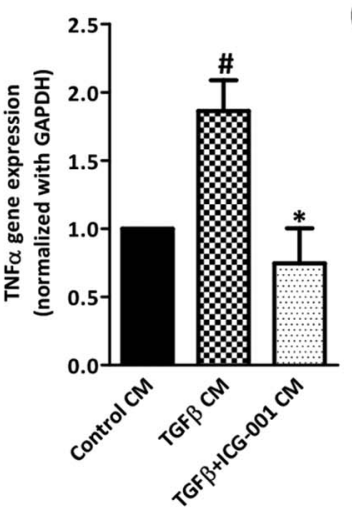

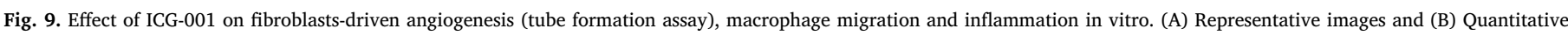

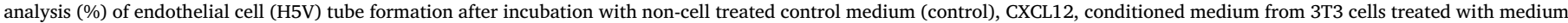

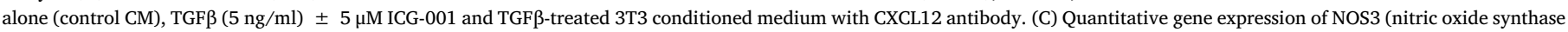

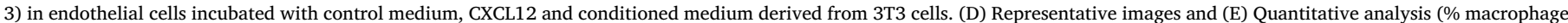

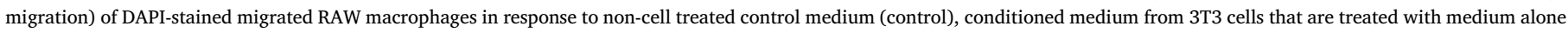

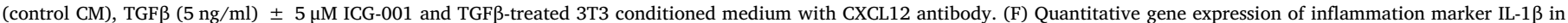

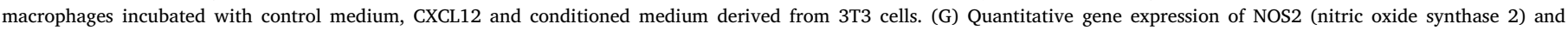

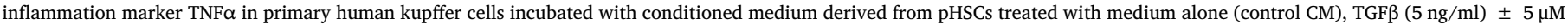

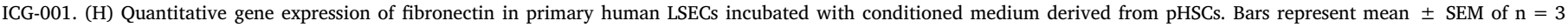
independent experiments. \#p $<0.05$, \#\#p $<0.01$ denotes significance versus control medium or control CM; *p $<0.05$, **p $<0.01$ denotes significance versus TGF $\beta$ CM.

significantly reduced resulting in attenuated fibrogenesis, inflammation and angiogenesis.

The main conclusion from our data is that following liver injury, quiescent hepatic stellate cells undergo trans-differentiation into activated HSCs accompanied with activation of canonical Wnt/ $\beta$-catenin signaling pathway. Activation of HSCs secretes soluble factors i.e. CXCL12 or SDF1 $\alpha$ which stimulates macrophage recruitment to liver and increased intrahepatic inflammation, and increased angiogenesis. CXCL12 also activates HSCs and therefore promote fibrogenesis further aggravated by increased inflammation and angiogenesis. Following inhibition of $\beta$-dependent Wnt signaling pathway, CXCL12 expression is reduced thereby attenuating intrahepatic inflammation, angiogenesis and fibrosis (Fig. 10).

Activation of the canonical Wnt pathways seems to be a critical feature of fibrotic diseases including systemic sclerosis, pulmonary, renal and liver fibrosis [22,25,27-29]. Inhibition/antagonism of this pathway in fibrotic diseases has been shown to inhibit fibrosis [30,32]. In accordance with other studies in different fibrotic diseases, we have 


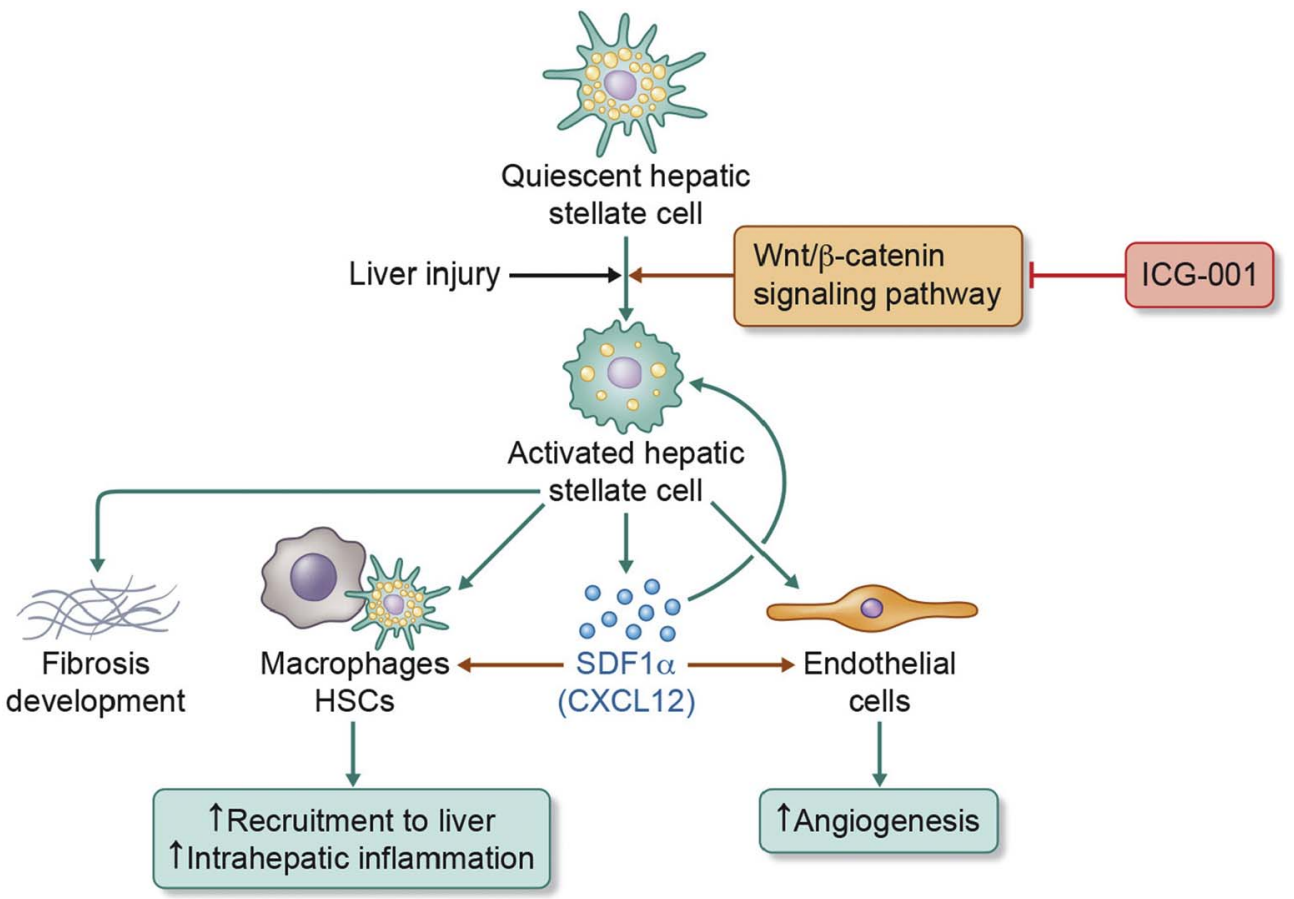

Fig. 10. Schematic representation depicting association of Wnt/ $\beta$-catenin pathway and CXCL12. Upon liver injury, quiescent hepatic stellate cells undergo trans-differentiation into activated hepatic stellate cells. This activation is facilitated by activation of Wnt/ $\beta$-catenin signaling pathway. Following activation, HSCs leads to fibrosis development and produce chemokines mainly CXCL12 and CXCL1. These chemokines in autocrine manner activates HSCs, and in paracrine fashion initiates recruitment of immune cells mainly macrophages and HSCs resulting in activation of macrophages and HSCs thereby leading to increased intrahepatic inflammation and fibrogenesis, and activation of endothelial cells resulting in increased angiogenesis. This activation process can be inhibited using Wnt/B-catenin pathway inhibitor ICG-001. also observed an overexpression of Wnts e.g. Wnt1, Wnt3a and Wnt10b in activated HSCs and early liver fibrosis $[25,29,46]$. Furthermore, we observed significant upregulation in the expression of Wnt frizzled receptors and LRP co-receptor as shown earlier [25,29,46]. In addition, we found activation of canonical Wnt signaling pathway with increased expression of $\beta$-catenin and increased transcription of target genes in activated HSCs and liver fibrosis as reported in organ fibrosis [25]. The activation of canonical Wnt signaling pathway is highly crucial for the HSCs activation and differentiation, and ECM production during fibrosis. Importantly, we have shown that inhibition of this pathway using selective $\beta$-catenin/CBP inhibitor ICG-001 significantly inhibits HSC activation, collagen deposition, HSC contraction and migration in vitro and strongly attenuates fibrogenesis, intrahepatic inflammation and angiogenesis in vivo.

Of particular interest, our data highlight the underlying mechanism involved in Wnt/ $\beta$-catenin induced fibrosis, inflammation and angiogenesis. We demonstrate that TGF $\beta$-induced activation of canonical Wnt pathway stimulates release of stromal factor SDF1 $\alpha /$ CXCL12 which plays a crucial paracrine molecule regulating HSCs activation; macrophage activation and migration; endothelial cells activation thereby influencing fibrogenesis, inflammation and angiogenesis respectively. To our best knowledge, this is the first study that shows the association of CXCL12 expression and activation of the Wnt/ß-catenin pathway in fibrosis especially in liver fibrosis. However more studies are warranted in different fibrotic diseases to confirm these findings. Furthermore, this study has been performed in acute liver fibrogenesis model that does not correspond to the clinical situation. Patients normally presents to the clinic when liver damage progresses to cirrhosis associated with portal hypertension and liver dysfunction. Nevertheless, this study provided first proof-of-concept results suggesting that selective inhibition of CXCL12 expression can be an promising therapeutic approach to be explored further in advanced models of liver cirrhosis.

In conclusion, canonical Wnt/ $\beta$-catenin plays a highly crucial role in fibrogenesis, inflammation and angiogenesis via CXCL12 expression and therefore downregulation of Wnt/ $\beta$-catenin pathway or selective inhibition of CXCL12 could be an effective strategy for the treatment of liver fibrosis.

\section{Transparency document}

The Transparency document associated with this article can be found, in the online version.

\section{Author contributions}

R. Bansal designed the research. B. Öztürk and R. Bansal performed research and analyzed data. R. Bansal wrote the paper. G. Storm provided the research facilities.

\section{Acknowledgements}

We thank B. Klomphaar for the technical assistance during the animal experiments. This project was supported by Netherlands Organization for Health Research and Development, ZonMw, NWO, VENI innovation grant 916.151 .94 (to R.B.).

\section{Competing financial interests}

The authors declare no competing financial interests.

\section{Appendix A. Supplementary data}

Supplementary data to this article can be found online at https:// doi.org/10.1016/j.bbadis.2017.12.001.

\section{References}

[1] D. Schuppan, N.H. Afdhal, Liver cirrhosis, Lancet 371 (2008) 838-851.

[2] S.L. Friedman, Hepatic fibrosis - overview, Toxicology 254 (2008) 120-129.

[3] S.L. Friedman, Mechanisms of hepatic fibrogenesis, Gastroenterology 134 (2008) 1655-1669.

[4] S. Lemoinne, A. Cadoret, H. El Mourabit, D. Thabut, C. Housset, Origins and functions of liver myofibroblasts, Biochim. Biophys. Acta 1832 (2013) 948-954.

[5] U.E. Lee, S.L. Friedman, Mechanisms of hepatic fibrogenesis, Baillieres Best Pract. Res. Clin. Gastroenterol. 25 (2011) 195-206.

[6] S.L. Friedman, Hepatic stellate cells: protean, multifunctional, and enigmatic cells of the liver, Physiol. Rev. 88 (2008) 125-172.

[7] S.D. Kershenobich, A.B. Weissbrod, Liver fibrosis and inflammation. A review, Ann. Hepatol. 2 (2003) 159-163.

[8] P. Ramachandran, A. Pellicoro, M.A. Vernon, L. Boulter, R.L. Aucott, A. Ali, 
S.N. Hartland, V.K. Snowdon, A. Cappon, T.T. Gordon-Walker, M.J. Williams, D.R. Dunbar, J.R. Manning, N. van Rooijen, J.A. Fallowfield, S.J. Forbes, J.P. Iredale, Differential Ly-6C expression identifies the recruited macrophage phenotype, which orchestrates the regression of murine liver fibrosis, Proc. Natl. Acad. Sci. U. S. A. 109 (2012) E3186-3195.

[9] T.A. Wynn, L. Barron, Macrophages: master regulators of inflammation and fibrosis, Semin. Liver Dis. 30 (2010) 245-257.

[10] F. Heymann, C. Trautwein, F. Tacke, Monocytes and macrophages as cellular targets in liver fibrosis, Inflamm. Allergy Drug Targets 8 (2009) 307-318.

[11] C. Paternostro, E. David, E. Novo, M. Parola, Hypoxia, angiogenesis and liver fibrogenesis in the progression of chronic liver diseases, World J. Gastroenterol. 16 (2010) 281-288.

[12] G.O. Elpek, Angiogenesis and liver fibrosis, World J. Hepatol. 7 (2015) 377-391.

[13] G. Xie, X. Wang, L. Wang, L. Wang, R.D. Atkinson, G.C. Kanel, W.A. Gaarde, L.D. Deleve, Role of differentiation of liver sinusoidal endothelial cells in progression and regression of hepatic fibrosis in rats, Gastroenterology 142 (2012) 918-927 (e916).

[14] L.D. DeLeve, Liver sinusoidal endothelial cells in hepatic fibrosis, Hepatology 61 (2015) 1740-1746.

[15] M.K. Connolly, A.S. Bedrosian, A. Malhotra, J.R. Henning, J. Ibrahim, V. Vera, N.E. Cieza-Rubio, B.U. Hassan, H.L. Pachter, S. Cohen, A.B. Frey, G. Miller, In hepatic fibrosis, liver sinusoidal endothelial cells acquire enhanced immunogenicity, J. Immunol. 185 (2010) 2200-2208.

[16] H. Tsukamoto, N.L. Zhu, J. Wang, K. Asahina, K. Machida, Morphogens and hepatic stellate cell fate regulation in chronic liver disease, J. Gastroenterol. Hepatol. 27 (Suppl. 2) (2012) 94-98.

[17] R. Bansal, J. van Baarlen, G. Storm, J. Prakash, The interplay of the Notch signaling in hepatic stellate cells and macrophages determines the fate of liver fibrogenesis, Sci. Rep. 5 (2015) 18272.

[18] R. van Amerongen, R. Nusse, Towards an integrated view of Wnt signaling in development, Development 136 (2009) 3205-3214.

[19] C.Y. Logan, R. Nusse, The Wnt signaling pathway in development and disease, Annu. Rev. Cell Dev. Biol. 20 (2004) 781-810.

[20] B.T. Macdonald, M.V. Semenov, X. He, SnapShot: Wnt/beta-catenin signaling, Cell 131 (2007) 1204.

[21] H. Huang, X. He, Wnt/beta-catenin signaling: new (and old) players and new insights, Curr. Opin. Cell Biol. 20 (2008) 119-125.

[22] R. Nusse, Wnt signaling in disease and in development, Cell Res. 15 (2005) 28-32.

[23] B.T. MacDonald, K. Tamai, X. He, Wnt/beta-catenin signaling: components, mechanisms, and diseases, Dev. Cell 17 (2009) 9-26.

[24] R.G. James, W.H. Conrad, R.T. Moon, Beta-catenin-independent Wnt pathways: signals, core proteins, and effectors, Methods Mol. Biol. 468 (2008) 131-144.

[25] A. Akhmetshina, K. Palumbo, C. Dees, C. Bergmann, P. Venalis, P. Zerr, A. Horn, T. Kireva, C. Beyer, J. Zwerina, H. Schneider, A. Sadowski, M.O. Riener, O.A. MacDougald, O. Distler, G. Schett, J.H. Distler, Activation of canonical Wnt signalling is required for TGF-beta-mediated fibrosis, Nat. Commun. 3 (2012) 735.

[26] J. Behari, The Wnt/beta-catenin signaling pathway in liver biology and disease, Expert Rev. Gastroenterol. Hepatol. 4 (2010) 745-756.

[27] C. Beyer, A. Schramm, A. Akhmetshina, C. Dees, T. Kireva, K. Gelse, S. Sonnylal, B. de Crombrugghe, M.M. Taketo, O. Distler, G. Schett, J.H. Distler, Beta-catenin is a central mediator of pro-fibrotic Wnt signaling in systemic sclerosis, Ann. Rheum. Dis. 71 (2012) 761-767.

[28] M. Chilosi, V. Poletti, A. Zamo, M. Lestani, L. Montagna, P. Piccoli, S. Pedron, M. Bertaso, A. Scarpa, B. Murer, A. Cancellieri, R. Maestro, G. Semenzato, C. Doglioni, Aberrant Wnt/beta-catenin pathway activation in idiopathic pulmonary fibrosis, Am. J. Pathol. 162 (2003) 1495-1502.

[29] W. He, C. Dai, Y. Li, G. Zeng, S.P. Monga, Y. Liu, Wnt/beta-catenin signaling promotes renal interstitial fibrosis, J. Am. Soc. Nephrol. 20 (2009) 765-776.

[30] W.R. Henderson Jr., E.Y. Chi, X. Ye, C. Nguyen, Y.T. Tien, B. Zhou, Z. Borok, D.A. Knight, M. Kahn, Inhibition of Wnt/beta-catenin/CREB binding protein (CBP) signaling reverses pulmonary fibrosis, Proc. Natl. Acad. Sci. U. S. A. 107 (2010) 14309-14314.

[31] M.D. Thompson, S.P. Monga, WNT/beta-catenin signaling in liver health and disease, Hepatology 45 (2007) 1298-1305.

[32] J.H. Cheng, H. She, Y.P. Han, J. Wang, S. Xiong, K. Asahina, H. Tsukamoto, Wnt antagonism inhibits hepatic stellate cell activation and liver fibrosis, Am. J. Physiol. Gastrointest. Liver Physiol. 294 (2008) G39-49.

[33] F. Jiang, C.J. Parsons, B. Stefanovic, Gene expression profile of quiescent and activated rat hepatic stellate cells implicates Wnt signaling pathway in activation, J. Hepatol. 45 (2006) 401-409.

[34] K.H. Emami, C. Nguyen, H. Ma, D.H. Kim, K.W. Jeong, M. Eguchi, R.T. Moon, J.L. Teo, H.Y. Kim, S.H. Moon, J.R. Ha, M. Kahn, A small molecule inhibitor of betacatenin/CREB-binding protein transcription [corrected], Proc. Natl. Acad. Sci. U. S. A. 101 (2004) 12682-12687.

[35] V.E. de Meijer, D.Y. Sverdlov, Y. Popov, H.D. Le, J.A. Meisel, V. Nose, D. Schuppan, M. Puder, Broad-spectrum matrix metalloproteinase inhibition curbs inflammation and liver injury but aggravates experimental liver fibrosis in mice, PLoS One 5 (2010) e11256.

[36] R.A. Norris, B. Damon, V. Mironov, V. Kasyanov, A. Ramamurthi, R. MorenoRodriguez, T. Trusk, J.D. Potts, R.L. Goodwin, J. Davis, S. Hoffman, X. Wen, Y. Sugi, C.B. Kern, C.H. Mjaatvedt, D.K. Turner, T. Oka, S.J. Conway, J.D. Molkentin, G. Forgacs, R.R. Markwald, Periostin regulates collagen fibrillogenesis and the biomechanical properties of connective tissues, J. Cell. Biochem. 101 (2007) 695-711.

[37] M.Y. Xu, J.J. Hu, J. Shen, M.L. Wang, Q.Q. Zhang, Y. Qu, L.G. Lu, Stat3 signaling activation crosslinking of TGF-betal in hepatic stellate cell exacerbates liver injury and fibrosis, Biochim. Biophys. Acta 1842 (2014) 2237-2245.

[38] Y. Xiao, C. Qu, W. Ge, B. Wang, J. Wu, L. Xu, Y. Chen, Depletion of thymosin beta4 promotes the proliferation, migration, and activation of human hepatic stellate cells, Cell. Physiol. Biochem. 34 (2014) 356-367.

[39] N. Uyama, L. Zhao, E. Van Rossen, Y. Hirako, H. Reynaert, D.H. Adams, Z. Xue, Z. Li, R. Robson, M. Pekny, A. Geerts, Hepatic stellate cells express synemin, a protein bridging intermediate filaments to focal adhesions, Gut 55 (2006) 1276-1289.

[40] R.P. Langhe, T. Gudzenko, M. Bachmann, S.F. Becker, C. Gonnermann, C. Winter, G. Abbruzzese, D. Alfandari, M.C. Kratzer, C.M. Franz, J. Kashef, Cadherin-11 localizes to focal adhesions and promotes cell-substrate adhesion, Nat. Commun. 7 (2016) 10909.

[41] E. Altrock, C. Sens, C. Wuerfel, M. Vasel, N. Kawelke, S. Dooley, J. Sottile, I.A. Nakchbandi, Inhibition of fibronectin deposition improves experimental liver fibrosis, J. Hepatol. 62 (2015) 625-633.

[42] S. Huveneers, H. Truong, R. Fassler, A. Sonnenberg, E.H. Danen, Binding of soluble fibronectin to integrin alpha5 beta1 - link to focal adhesion redistribution and contractile shape, J. Cell Sci. 121 (2008) 2452-2462.

[43] C. Margadant, A. Sonnenberg, Integrin-TGF-beta crosstalk in fibrosis, cancer and wound healing, EMBO Rep. 11 (2010) 97-105.

[44] Y. Saiman, J. Jiao, M.I. Fiel, S.L. Friedman, C. Aloman, M.B. Bansal, Inhibition of the CXCL12/CXCR4 chemokine axis with AMD3100, a CXCR4 small molecule inhibitor, worsens murine hepatic injury, Hepatol. Res. 45 (2015) 794-803.

[45] S.K. Ramasamy, A.P. Kusumbe, L. Wang, R.H. Adams, Endothelial Notch activity promotes angiogenesis and osteogenesis in bone, Nature 507 (2014) 376-380.

[46] L. Corbett, J. Mann, D.A. Mann, Non-canonical Wnt predominates in activated rat hepatic stellate cells, influencing HSC survival and paracrine stimulation of Kupffer cells, PLoS One 10 (2015) e0142794. 